\title{
The First Year in Review: \\ NASA's Ares I Crew Launch Vehicle and Ares V Cargo Launch Vehicle
}

\author{
Daniel L. Dumbacher, Deputy Director \\ and \\ James L. Reuter, Vehicle Integration Manager \\ Exploration Launch Projects Office \\ NASA Marshall Space Flight Center \\ Huntsville, AL 35812
}

\begin{abstract}
The U.S. Vision for Space Exploration guides NASA's challenging missions of scientific discovery.' Developing safe, reliable, and affordable space transportation systems for the human and robotic exploration of space is a key component of fulfilling the strategic goals outlined in the Vision, as well as in the U.S. Space Policy. ${ }^{2}$ In October 2005, the Exploration Systems Mission Directorate and its Constellation Program chartered the Exploration Launch Projects Office, located at the Marshall Space Flight Center, to design, develop, test, and field a new generation of launch vehicles that would fulfill customer and stakeholder requirements for trips to the Moon, Mars, and beyond.

The Ares I crew launch vehicle is slated to loft the Orion crew exploration vehicle to orbit by 2014, while the heavy-lift Ares V cargo launch vehicle will deliver the lunar lander to orbit by 2020 (Fig. 1). These systems are being designed to empower America's return to the Moon to prepare for the first astronaut on Mars. The new launch vehicle designs now under study reflect almost 50 years of hard-won experience gained from the Saturn's missions to the Moon in the late 1960s and early 1970s, and from the venerable Space Shuttle, which is due to be retired by 2010 .
\end{abstract}

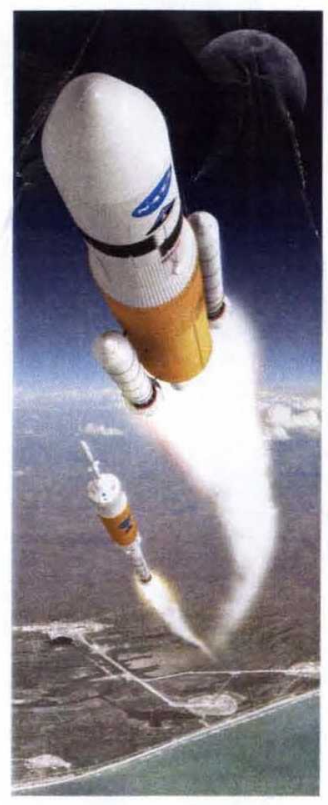

Fig. 1. NASA concept of America's new launch vehicles-Ares I (bottom) and Ares V. 
The genesis of activities now under way by a nationwide government and industry team began with the confirmation of the current NASA Administrator, Dr. Michael Griffin, in April 2005. Shortly thereafter, he commissioned a team of aerospace experts to conduct the Exploration Systems Architecture Study (ESAS). ${ }^{3}$ Through the summer of 2005, the ESAS team examined a number of potential space transportation solutions, investigating both Shuttle-derived and Evolved Expendable Launch Vehicle combinations. The ESAS Report, delivered in fall 2005, provided starting-point recommendations for the range of exploration architecture components, including the crew capsule and lunar systems, while this paper focuses on the launch vehicle designs and their evolution during the first year of this expansive effort. It also provides top-level schedules and representative management and hardware accomplishments for each of the two launch vehicles.

In October 2005, the streamlined Exploration Launch Projects Office began forming the team and putting into place the partnerships (Fig. 2) that will yield new space transportation systems. By applying modern design methodologies and consulting with senior aerospace experts, the Exploration Launch Projects team has refined the ESAS point-of-departure options following systems engineering standards and business best practices. In this way, technical performance has been continually assessed from the standpoint of cost as an independent variable and in relation to the desired timeline, mindful of the Agency's safety standards and pay-as-you-go philosophy.

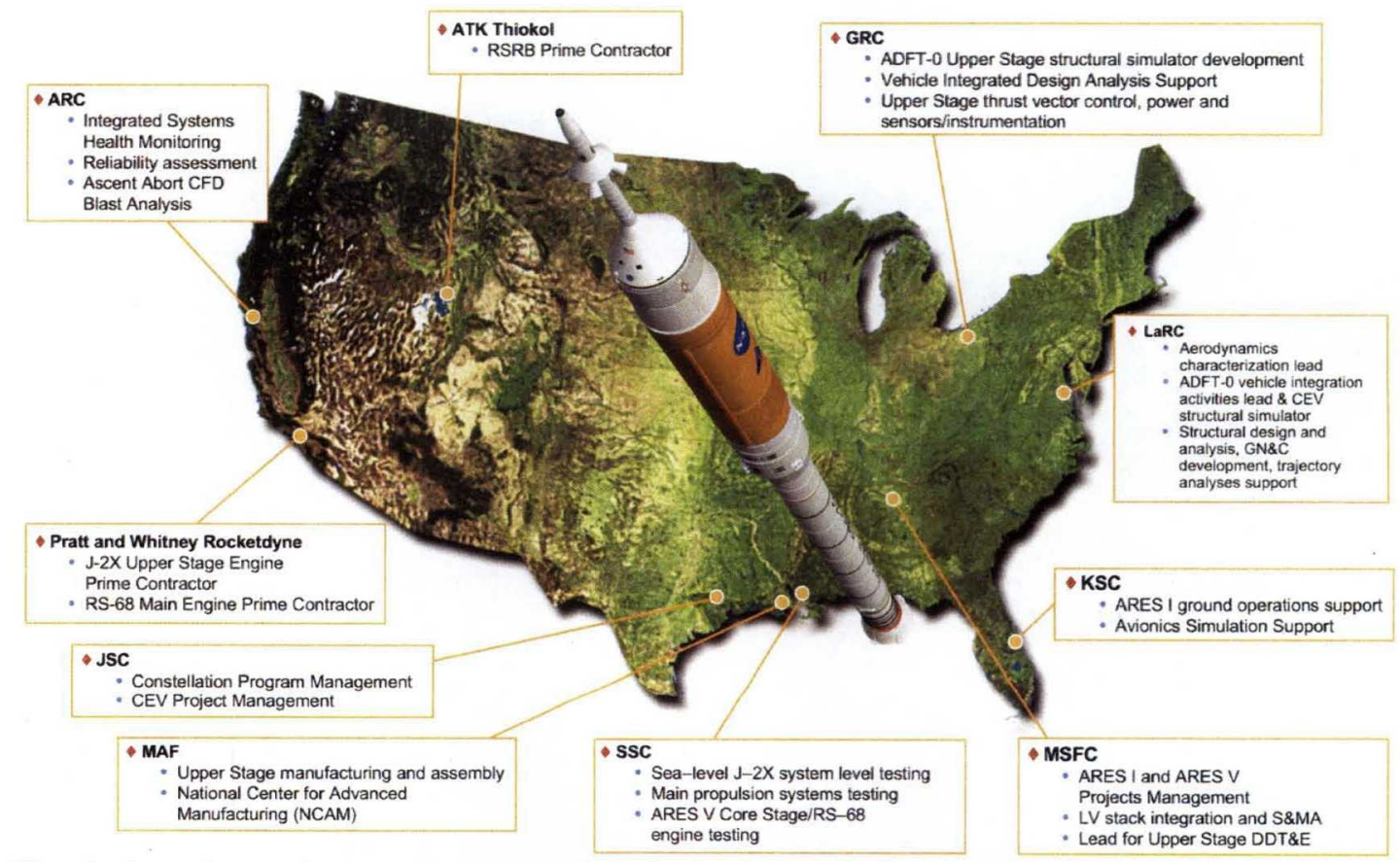

Fig. 2. A nationwide team is engaged in designing and developing the Ares I and Ares V.

The resulting designs, approved by the Constellation Program Control Board, build on a foundation of reliable propulsion systems, combined with updated avionics, thermal protection materials, computers, electronics, and other state-of-the-art enhancements. Fig. 3 compares the current launch vehicle configurations and the legacy systems from which the new ones will be derived. By building upon proven hardware, leveraging synergy between systems, and evolving the vehicle concepts to meet or exceed safety, technical, cost, and schedule requirements, NASA has significantly condensed the number of propulsion elements it has to develop, thereby reducing overall program risks and costs. 


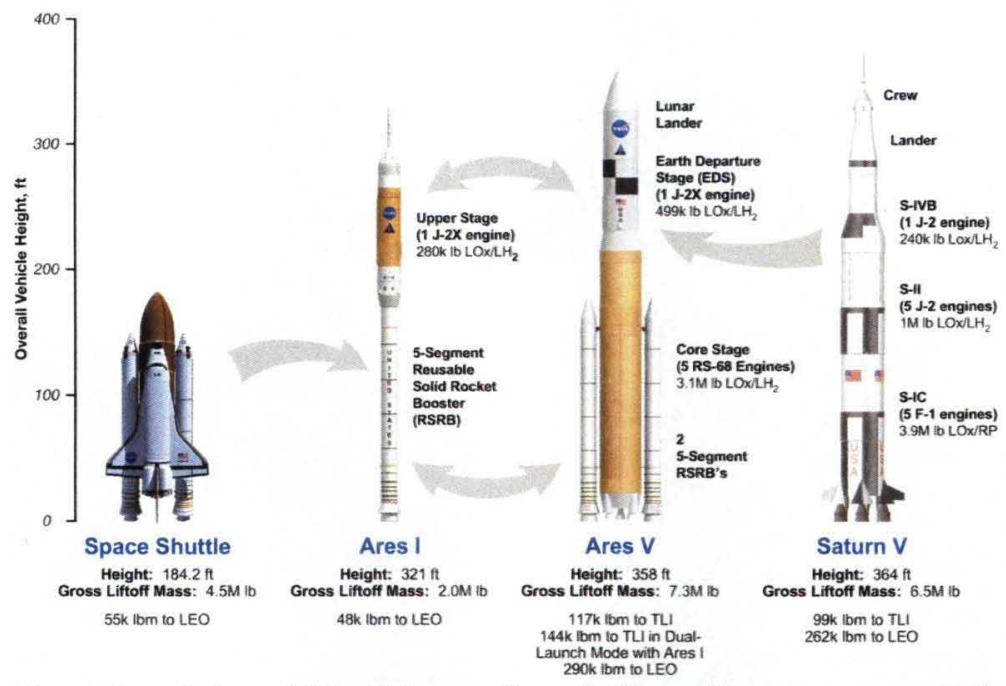

Fig. 3. The Ares I and Ares V build on a foundation of proven propulsion systems.

The current Ares I launch vehicle concept (Fig. 4) represents the culmination of two design analysis cycles, leading to the Ares I System Requirements Review. The Ares V baseline, also shown in Fig. 4, has completed its first design analysis cycle, as funding is being provided at a lower level for this second system. These are derivations of the options put forth by the ESAS, with its crew launch vehicle design that was to be powered by a 4-segment Reusable Solid Rocket Booster (RSRB) first stage and an upper stage powered by a Space Shuttle Main Engine (SSME) modified to start at altitude and restart on orbit. The initial cargo configuration consisted of two 5-segment RSRBs and yet another low-cost, highproduction-rate version of the SSME for the core propulsion stage, with the J-2X engine powering the Earth departure stage, for a total of five major propulsion developments.

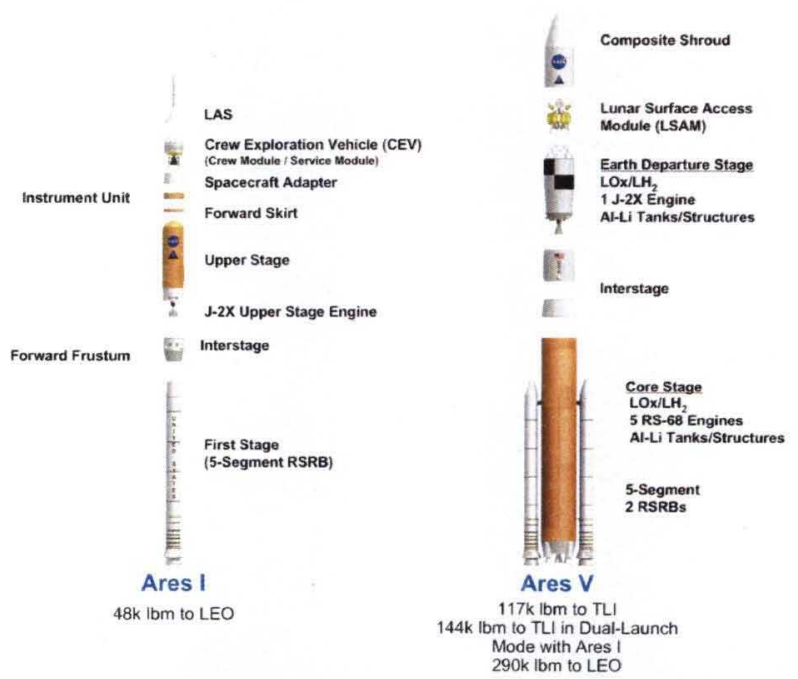

Fig. 4. Expanded views of the Ares I and Ares V. 
As trade studies and business analyses progressed, it became evident that using common hardware for the two systems would reduce overall technical, cost, and schedule risks. Now, the Ares I includes a 5segment RSRB, similar to those that will be used for the Ares V core propulsion, and a J-2X engine for both vehicle upper stages. In addition, the commercially available RS-68 was selected for the Ares V core stage main engine, saving considerable operations costs across decades of operations. Concentrating efforts on two major propulsion developments rather than on five, as was originally proposed, will reduce development costs by hundreds of millions of dollars in the near term and save billions in operations expenses, helping meet the requirement to significantly reduce life-cycle costs so that NASA can focus more of its limited resources on the scientific discovery that space transportation enables.

Engineering America's next fleet of spacecraft demands that safety, reliability, and operability are maximized for missions to the International Space Station, as well as for America's lunar exploration in preparation for much longer journeys and the first human footprint on Mars. The Exploration team employs sound systems engineering and business best practices to effectively fuse the many subsystem elements and components that form an integrated system suitable for sustainable long-term exploration. The process of successively refining the vehicle concept through a number of design analysis cycles includes trade studies that are conducted with state-of-the-art tools, documented in official reports, and approved through a governing board structure utilizing a disciplined configuration/data management control process. ${ }^{4}$

Reflecting a carefully formulated integrated master schedule (Fig. 5), the Ares I System Requirements Review milestone is set to kick off in November 2006, just 1 year after building the team, performing extensive analyses, and laying the procurement framework to empower a design effort of this magnitude. This review is focused on requirements validation and verification, risk identification and mitigation, as well as baselining the reference design from which to continue systems engineering work, leading to the Preliminary Design Review in 2008.

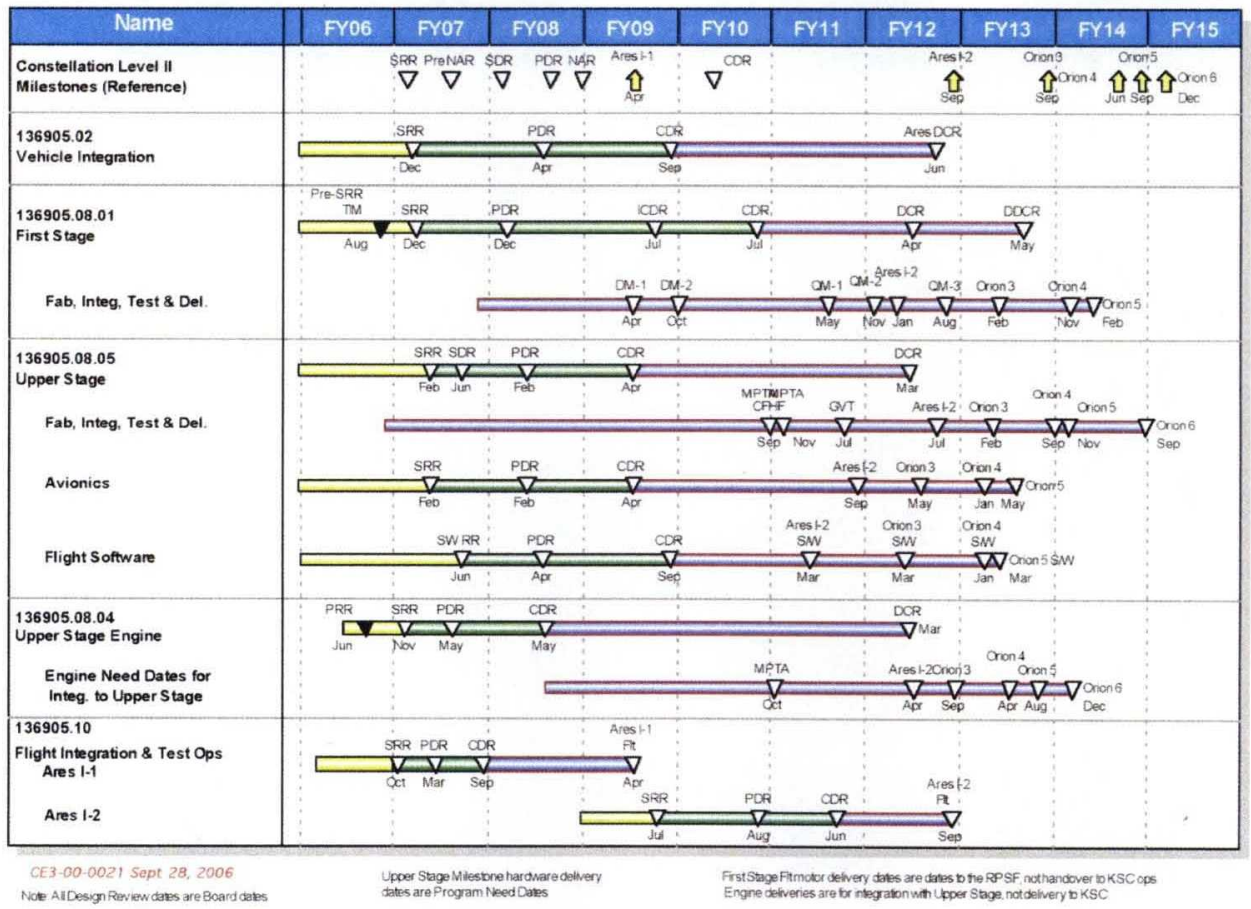

Fig. 5. Ares I schedule. 
Progress also has been made toward planning the first flight of the integrated system, a mission known as Ares I-1, which is scheduled for spring 2009 (Fig. 6). The Ares I-1 vehicle will be composed of a mixture of flight and high-fidelity mockup hardware to simulate the aerodynamics and loads of the anticipated full-up Ares I mission. Following a test-as-you-fly philosophy, data gathered from this flight will inform the next major milestone - the Critical Design Review in late 2009. Flying the Ares I-1 gives an early opportunity to perform proof-of concept testing of the first stage's Reusable Solid Rocket Booster hardware, which will be evolved and repurposed for the Ares application, as well as to gather data about the dynamics of the integrated launch vehicle stack. In addition, as the Kennedy Space Center transitions from Space Shuttle to the Ares/Orion system, the Ares I-1 mission provides an excellent starting point from which to perfect ground operations scenarios, including modifications to Launch Complex $39 \mathrm{~B}$.

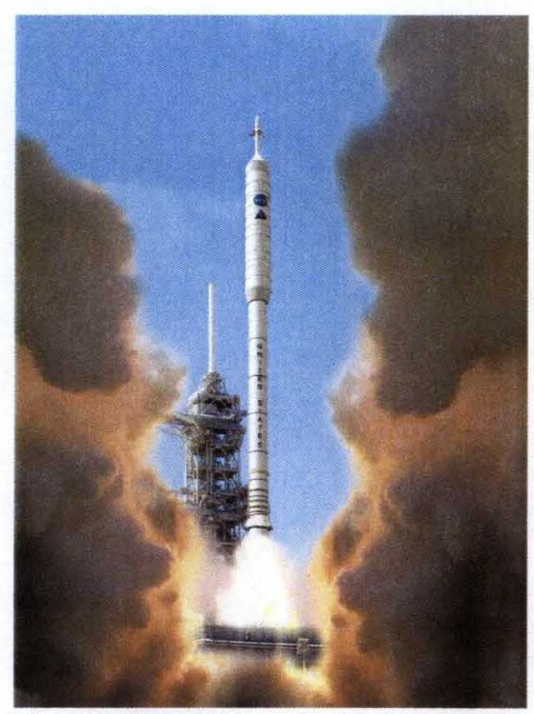

Fig. 6. Ares I-1 mission concept.

During this inaugural year, the Ares $\mathrm{V}$ has completed its first design analysis cycle, and the current baseline now includes the commercially available RS-68 core stage engine. NASA and the U.S. Air Force are teaming to upgrade the engine for future missions, reducing technical, schedule, and cost risk. While most work in the past year has been focused on the Ares I, with common hardware accomplishments benefiting the Ares $\mathrm{V}$, business and technical planning has produced a logic-linked Ares $\mathrm{V}$ integrated master schedule (Fig. 7). This next generation heavy-lift system is on track to provide the capability needed to return Americans to the Moon late next decade and to ensure the nation's access to space for national security and economic expansion. 
PCB B/L 5/18/06

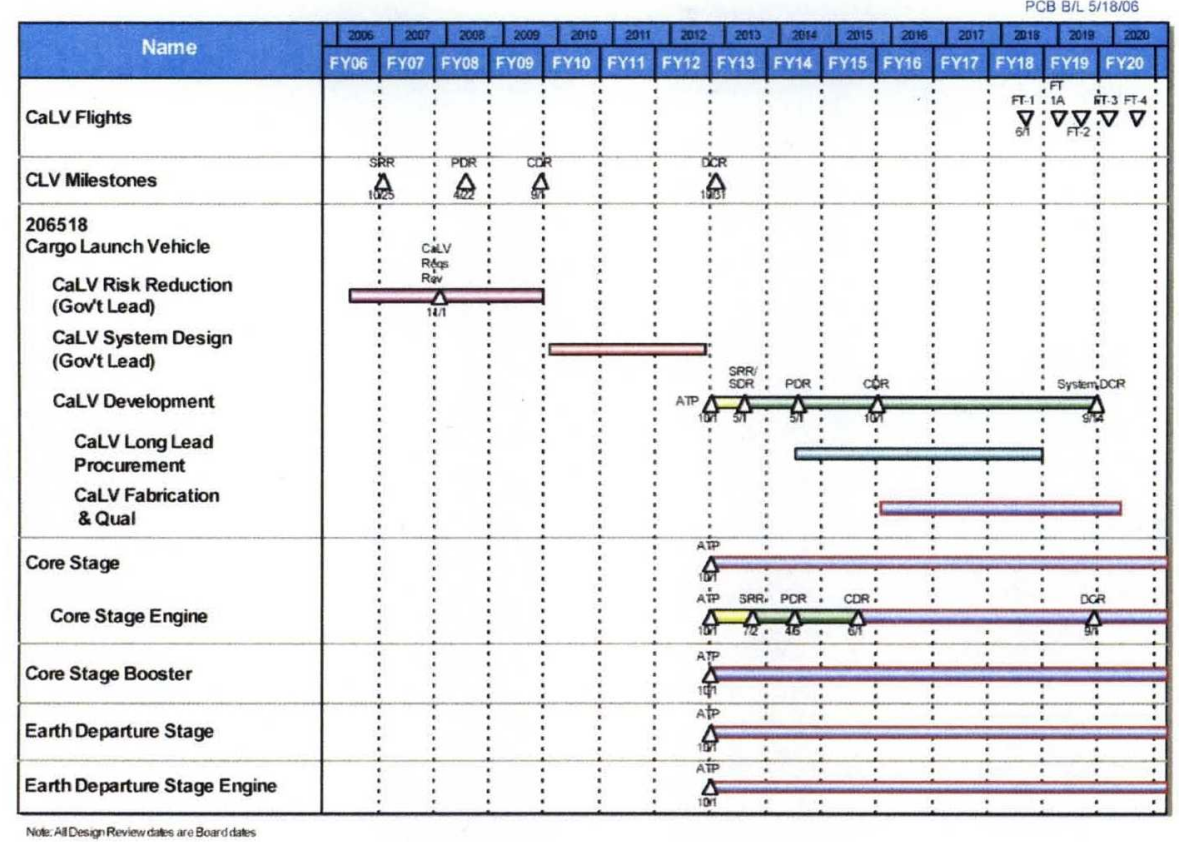

Fig. 7. Ares V schedule.

\section{References}

1. National Aeronautics and Space Administration, The Vision for Space Exploration, February 2004, www.NASA.gov.

2. U.S. National Space Policy, 2006. http://www.ostp.gov/

3. National Aeronautics and Space Administration, NASA's Exploration Systems Architecture Study Final Report, November 2005, NASA-TM-2005-214062.

4. Johnson, Stephen B., The Secret of Apollo, The Johns Hopkins University Press, 2002. 


\title{
The First Year in Review: NASA's Ares I Crew Launch Vehicle and Ares V Cargo Launch Vehicle
}

\author{
Daniel L. Dumbacher, Director of Engineering \\ and \\ James L. Reuter, Vehicle Integration Manager \\ Exploration Launch Projects Office \\ NASA Marshall Space Flight Center \\ Huntsville, AL 35812
}

\begin{abstract}
In its inaugural year of operations, the Exploration Launch Projects Office has accomplished a phenomenal amount of work, maturing the design of the Ares I Crew Launch Vehicle and Ares V Cargo Launch Vehicle from the original proposals of the Exploration Systems Architecture Study (ESAS) to a level of fidelity that allowed the project to successfully complete its first major milestone review. In addition to refining the vehicle designs, the Project has made plans and begun development for the first test flight of the new crew vehicle design, scheduled for 2009.
\end{abstract}

\section{Introduction}

The U.S. Vision for Space Exploration guides NASA's challenging missions of scientific discovery. ${ }^{1}$ Developing safe, reliable, and affordable space transportation systems for the human and robotic exploration of space is a key component of fulfilling the strategic goals outlined in the Vision, as well as in the U.S. Space Policy. ${ }^{2}$ In October 2005, the Exploration Systems Mission Directorate and its Constellation Program chartered the Exploration Launch Projects Office, located at the Marshall Space Flight Center, to design, develop, test, and field a new generation of launch vehicles that would fulfill customer and stakeholder requirements for trips to the Moon, Mars, and beyond.

The Ares I crew launch vehicle is slated to loft the Orion crew exploration vehicle to orbit by 2015 , while the heavylift Ares V cargo launch vehicle will deliver the lunar lander to orbit by 2020 (Fig. 1). These systems are being designed to empower America's return to the Moon to prepare for the first astronaut on Mars. The new launch vehicle designs now under study reflect almost 50 years of hard-won experience gained from the Saturn's missions to the Moon in the late 1960s and early 1970s, and from the venerable Space Shuttle, which is due to be retired by 2010.

The genesis of activities now under way by a nationwide government and industry team began with the confirmation of the current NASA Administrator, Dr. Michael Griffin, in April 2005. Shortly thereafter, he commissioned a team of aerospace experts to conduct the Exploration Systems Architecture Study (ESAS). ${ }^{3}$ Through the summer of 2005, the ESAS team examined a number of potential space transportation solutions, investigating both Shuttle-derived and Evolved Expendable Launch Vehicle combinations. The ESAS Report, delivered in fall 2005, provided startingpoint recommendations for the range of exploration architecture components, including the crew capsule and lunar systems, while this paper focuses on the launch vehicle designs and their evolution during the first year of this expansive effort. It also provides top-level schedules and representative management and hardware accomplishments for each of the two launch vehicles. 


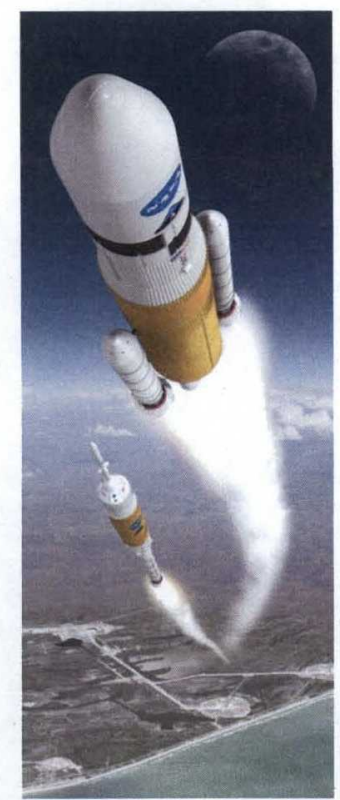

Fig. 1. NASA concept of America's new launch vehicles-Ares I (bottom) and Ares V.

In October 2005, the streamlined Exploration Launch Projects Office began forming the team and putting into place the partnerships (Fig. 2) that will yield new space transportation systems. By applying modern design methodologies and consulting with senior aerospace experts, the Exploration Launch Projects team has refined the ESAS point-ofdeparture options following systems engineering standards and business best practices. In this way, technical performance has been continually assessed from the standpoint of cost as an independent variable and in relation to the desired timeline, mindful of the Agency's safety standards and pay-as-you-go philosophy.

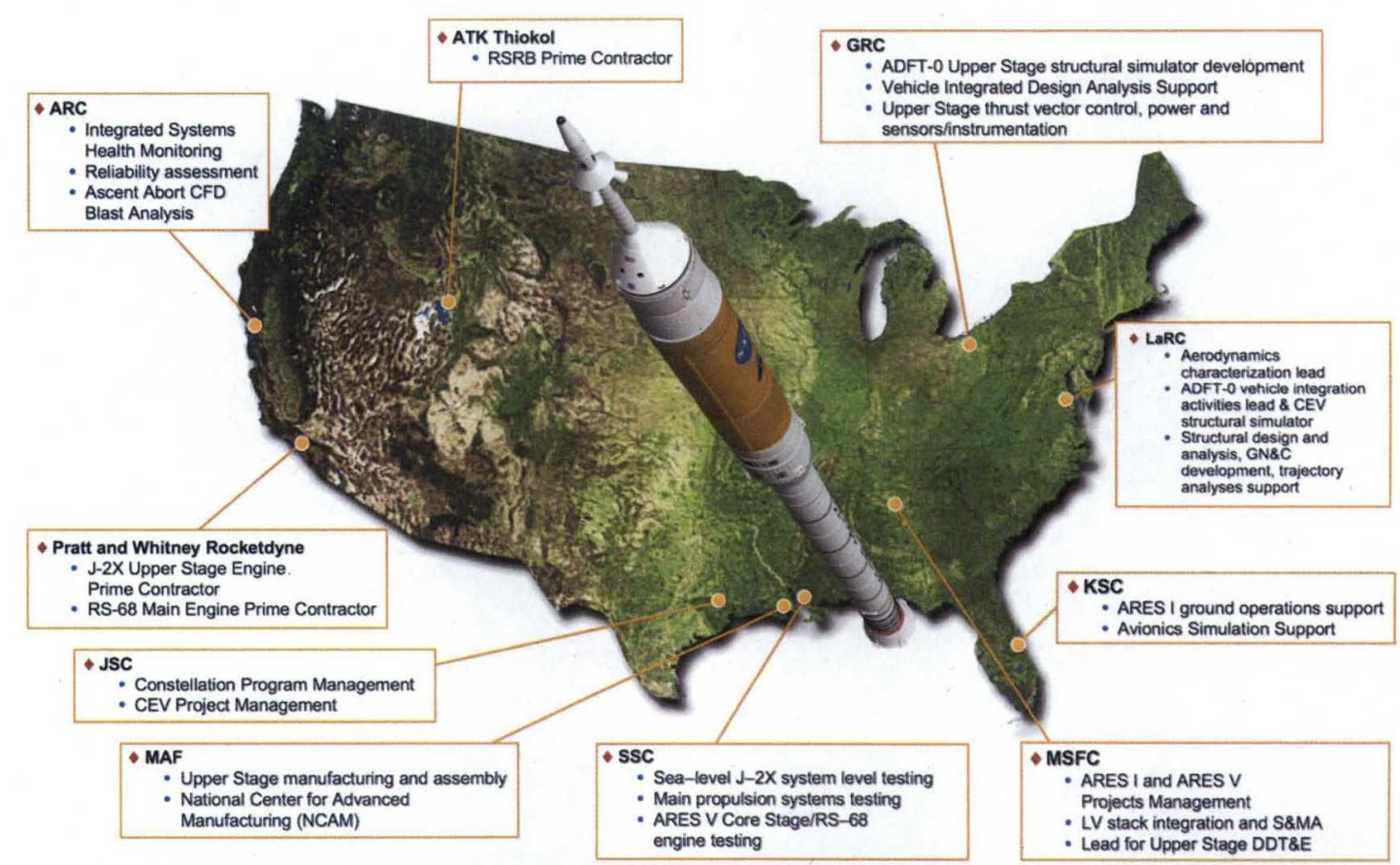

Fig. 2. A nationwide team is engaged in designing and developing the Ares I and Ares V. 
The resulting designs, approved by the Constellation Program Control Board, build on a foundation of reliable propulsion systems, combined with updated avionics, thermal protection materials, computers, electronics, and other state-of-the-art enhancements. Fig. 3 compares the current launch vehicle configurations and the legacy systems from which the new ones will be derived. By building upon proven hardware, leveraging synergy between systems, and evolving the vehicle concepts to meet or exceed safety, technical, cost, and schedule requirements, NASA has significantly condensed the number of propulsion elements it has to develop, thereby reducing overall program risks and costs.

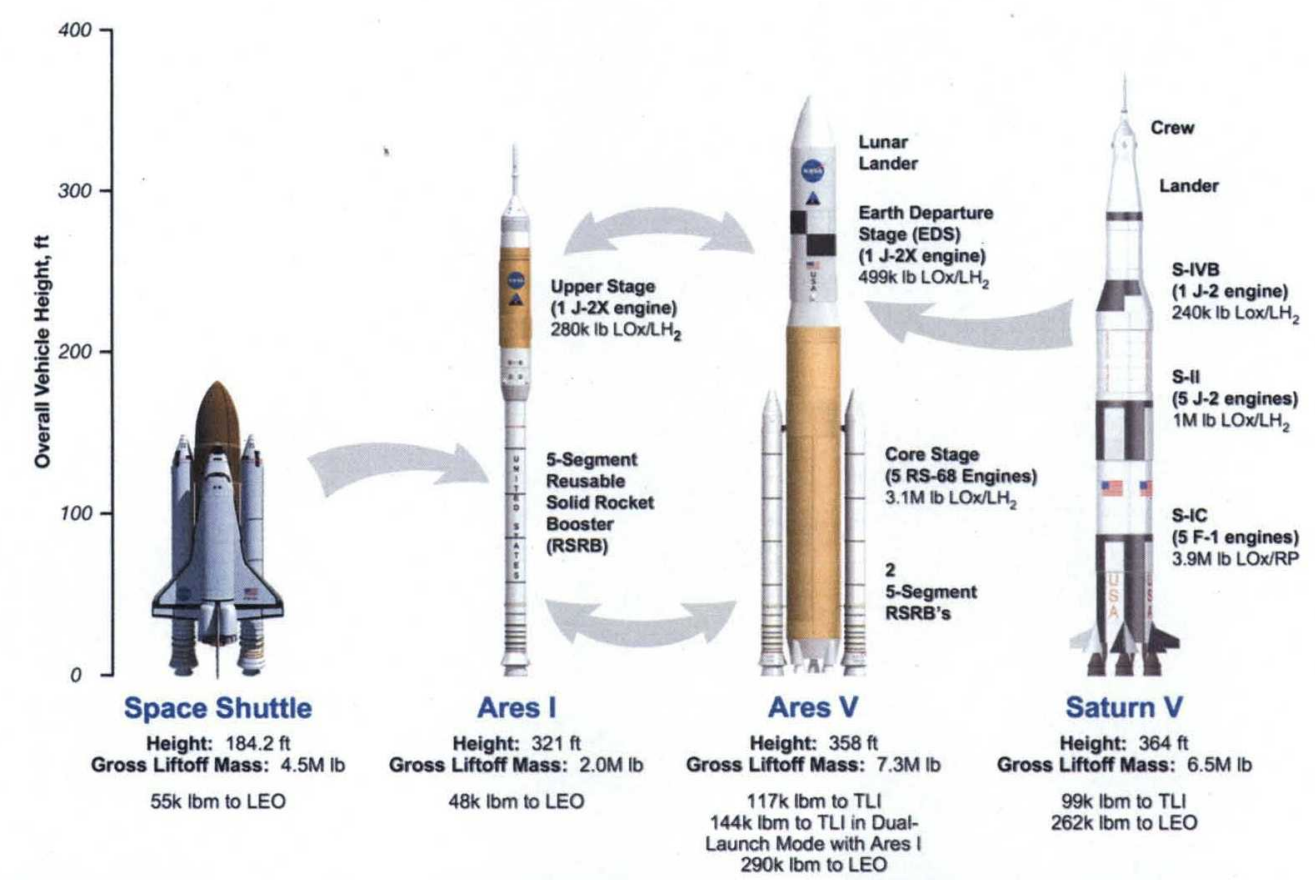

Fig. 3. The Ares I and Ares V build on a foundation of proven propulsion systems.

\section{Vehicle Design Evolution}

The current Ares I launch vehicle concept (Fig. 4) represent the culmination of two design analysis cycles, leading to the Ares I System Requirements Review. The current design is a derivation of the option put forth by the ESAS, which utilized a 4-segment Reusable Solid Rocket Booster (RSRB) first stage and an upper stage powered by a Space Shuttle Main Engine (SSME) modified to start at altitude and restart on orbit.

As trade studies and business analyses progressed, it became evident that using common hardware for the two systems would reduce overall technical, cost, and schedule risks. Now, the Ares I includes a 5-segment RSRB, similar to those that will be used for the Ares $\mathrm{V}$ core propulsion, and will utilize the same upper stage J-2X engine planned for use on the Ares V Earth departure stage. In addition to this move to common hardware, the Ares I design now utilizes a common bulkhead for the upper stage liquid oxygen and liquid hydrogen tanks. This common bulkhead, while a more complex design from a manufacturing standpoint, results in significant savings in the vehicle's liftoff mass and, therefore, improves performance to help meet the mission requirements.

The Ares V baseline, also shown in Fig. 4, has completed its first design analysis cycle, as funding is being provided at a lower level for this second system. The initial cargo configuration consisted of two 5-segment RSRBs and yet another low-cost, high-production-rate version of the SSME for the core propulsion stage, with the J-2X engine powering the Earth departure stage. In an effort to cut cost and schedule risks, the commercially available RS-68 was selected to replace the proposed SSME for the Ares V core stage main engine, saving considerable recurring costs across decades of operations. 
Overall, this inaugural year of the project's life-cycle saw dozens of distinct trade studies conducted to compare a huge variety of design options and operational concepts. The end result is a vehicle design that has been examined from every angle to ensure the best technical solutions to engineering challenges, as well as the best utilization of the resources provided by the American taxpayers. Concentrating efforts on two major propulsion developments rather than on five, as was originally proposed, will reduce development costs by hundreds of millions of dollars in the near term and save billions in operations expenses, helping meet the requirement to significantly reduce lifecycle costs so that NASA can focus more of its limited resources on the scientific discovery that space transportation enables.

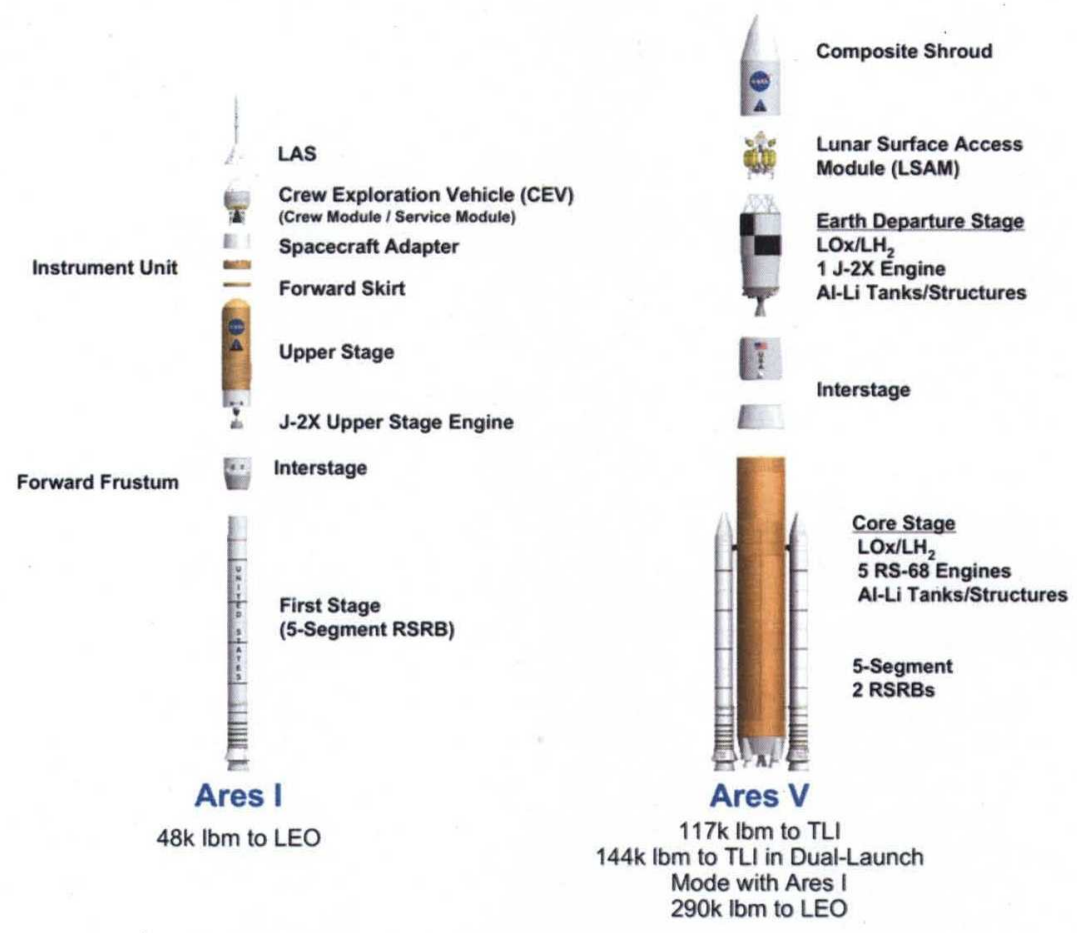

Fig. 4. Expanded views of the Ares I and Ares V.

\section{Management Philosophy and Major Milestones}

Engineering America's next fleet of spacecraft demands that safety, reliability, and operability are maximized for missions to the International Space Station, as well as for America's lunar exploration in preparation for much longer journeys and the first human footprint on Mars. The Exploration team employs sound systems engineering and business best practices to effectively fuse the many subsystem elements and components that form an integrated system suitable for sustainable long-term exploration. The process of successively refining the vehicle concept through a number of design analysis cycles includes trade studies that are conducted with state-of-the-art tools, documented in official reports, and approved through a governing board structure utilizing a disciplined configuration/data management control process. ${ }^{4}$

Reflecting a carefully formulated integrated master schedule (Fig. 5), the Ares I System Requirements Review (SRR) was conducted in November 2006, just 1 year after building the team, performing extensive analyses, and laying the procurement framework to empower a design effort of this magnitude. The review included analysis of 49 separate documents, including system requirements definition, interface definition, and operations concept documents. This review was focused on requirements validation and verification, risk identification and mitigation, as well as baselining the reference design from which to continue systems engineering work, leading to the Systems Design Review (SDR) in September 2007 and Preliminary Design Review (PDR) in 2008.

The SRR objectives were to confirm that all the Ares I system requirements were complete, validated, allocated to the appropriate element level, and responsive to mission requirements as spelled out in the Constellation 
Architecture Requirements Document. As part of this activity, all outstanding issues to be resolved had identified resolution plans. In addition, the review established that the Ares I architecture and conceptual design was capable of fulfilling the mission objectives within the imposed constraints. Having successfully completed this review, the Project has begun the engineering design activities to bring the Ares I design to the appropriate maturity level for SDR, and to PDR beyond that.

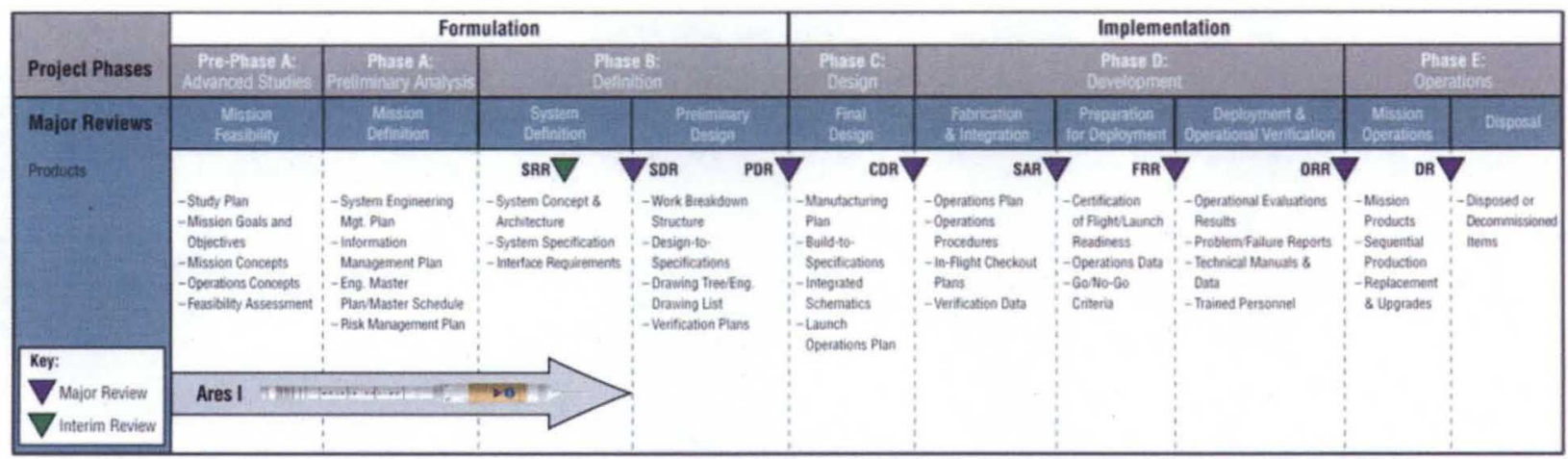

Fig. 5. Ares I schedule.

\section{First Steps — The Ares I-X Development Flight Test}

Progress also has been made toward planning the first flight of the integrated system, a mission known as Ares I-X, which is scheduled for April 2009 (Fig. 6). The Ares I-X vehicle will be composed of flight and high-fidelity mockup hardware to simulate the anticipated aerodynamics and loads of the anticipated full-up Ares I mission. The first stage will be a 5-segment RSRB, though the fifth segment will be a mass simulator, and the upper stage will be a mock-up to simulate the mass, center of gravity, and outer mold line of the final flight hardware in development. Atop the mock upper stage, a mass simulator will represent the Orion crew exploration vehicle, designed to accurately reflect the aerodynamics of the planned crew capsule.

Following a test-as-you-fly philosophy, data gathered from this initial suborbital flight will inform the next major milestone - the Critical Design Review in late 2009. Flying the Ares I-X provides an early opportunity to perform proof-of-concept testing of the first stage's Reusable Solid Rocket Booster hardware, which will be evolved and repurposed for the Ares application, as well as to gather data about the dynamics of the integrated launch vehicle stack. In addition, as the Kennedy Space Center transitions from Space Shuttle to the Ares/Orion system, the Ares I$\mathrm{X}$ mission provides an excellent starting point from which to perfect ground operations scenarios, including modifications to Launch Complex 39B.

To aid in streamlining operational processes, such as the Certificate of Flight Readiness (COFR), the Ares I-X test flight organization has been made a separate mission office under the Constellation Program, with both the Flight Test Vehicle (FTV) and Ground Operations (GO) elements reporting to a single Project Manager. Further, to reduce decision and approval times, the Ares I-X Project will reduce its number of independent review boards from ten to a much more reasonable four. These organizational changes will promote the Ares I-X mission reaction time to meet the targeted April 2009 launch date. 


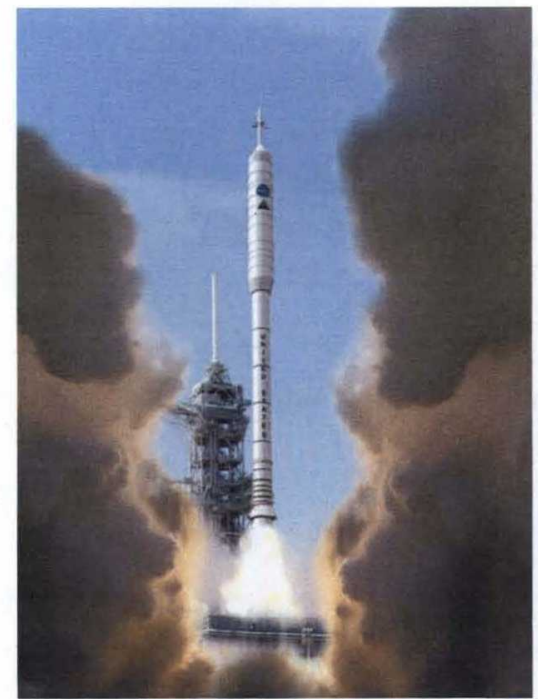

Fig. 6. Ares I-X mission concept.

\section{Ares V - Looking to the Moon and Beyond}

During this inaugural year, the Ares $\mathrm{V}$ has completed its first design analysis cycle, and the current baseline now includes the commercially available RS-68 core stage engine. NASA and the U.S. Air Force are teaming to upgrade the engine for future missions, reducing technical, schedule, and cost risk. While most work in the past year has been focused on the Ares I, with common hardware accomplishments benefiting the Ares V, business and technical planning hs produced a logic-linked Ares $\mathrm{V}$ integrated master schedule (Fig. 7). This next generation heavy-lift system is on track to provide the capability needed to return Americans to the Moon late next decade and to ensure the nation's access to space for national security and economic expansion.

NASA's exploration plans initially called for development of the heavy-lift Ares V cargo launch vehicle to begin in 2012. However, Congressional conferees noted in their 2006 Appropriations bill that "the Heavy Lift Launch Vehicle is critical to NASA's exploration plans" and that "human exploration beyond low Earth orbit is not achievable without an operational capability." They provided \$5 million in FY 2006 and \$3.2 million in FY 2007 as seed money to support early development of a heavy lift launch capability.

Trade studies in early 2006 changed the Ares V Core Stage engine from a modified Space Shuttle Main Engine to a more easily upgraded variant of the commercially available RS-68 engine. NASA invested the seed money in identifying detailed requirements for modifying the RS-68. The agency conducted early risk mitigation testing on engine components, and initiated a relationship with the U.S. Air Force to develop a common engine to satisfy the needs of both agencies. With that funding exhausted and as a result of the congressional continuing resolution, NASA is archiving its work to date and plans to resume Ares V development in 2011 in accordance with its original plan. In the meantime, NASA will continue to define requirements and refine preliminary designs for the Ares V and share data and expertise with the Air Force on RS-68 development, testing, and flight. 


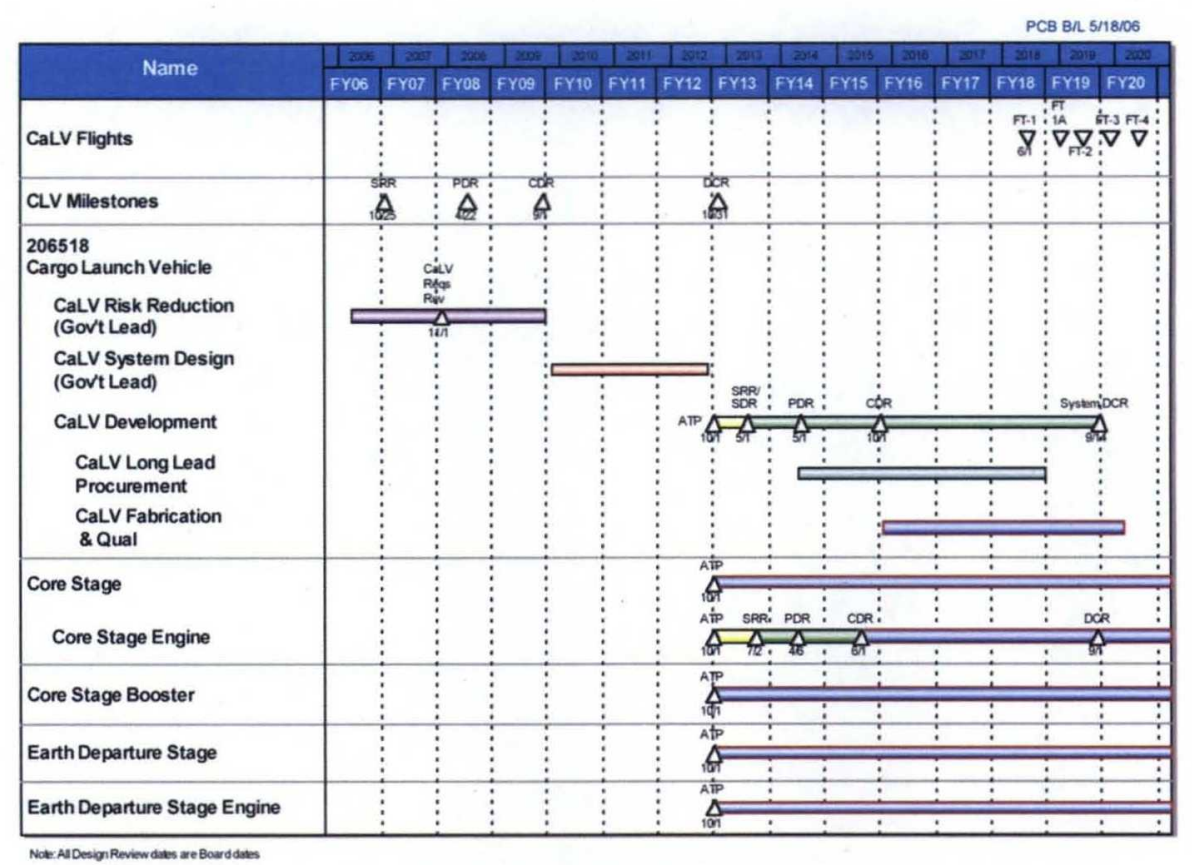

Fig. 7. Ares V schedule.

\section{Summary}

The Ares I and Ares V will restore long-absent exploratory capabilities to U.S. space endeavors. In one short year, the Exploration Launch Projects Office has made great strides in developing these new spacecraft, and established a work ethic and a schedule that leads us back to the Moon and on to Mars. A nationwide team of Agency and industry partners is now in place to carry the development forward. The system requirements review has established that the current designs are capable of achieving the metrics defined by the Constellation Program, and the Project now prepares for the first major design review in September 2007. Meanwhile, the Ares I-X mission continues its preparations to fly in 2009, providing the Ares design team with valuable data to use in refining the Ares I design. This level of progress and planning demonstrates the Agency's commitment to moving America's space fleet into the 21 st century, ensuring our access to and exploration of space for generations to come.

\section{References}

1. National Aeronautics and Space Administration, The Vision for Space Exploration, February 2004, www.NASA.gov.

2. U.S. National Space Policy, 2006. http://www.ostp.gov/

3. National Aeronautics and Space Administration, NASA's Exploration Systems Architecture Study Final Report, November 2005, NASA-TM-2005-214062.

4. Johnson, Stephen B., The Secret of Apollo, The Johns Hopkins University Press, 2002.

5. 2006 Appropriations Bill 


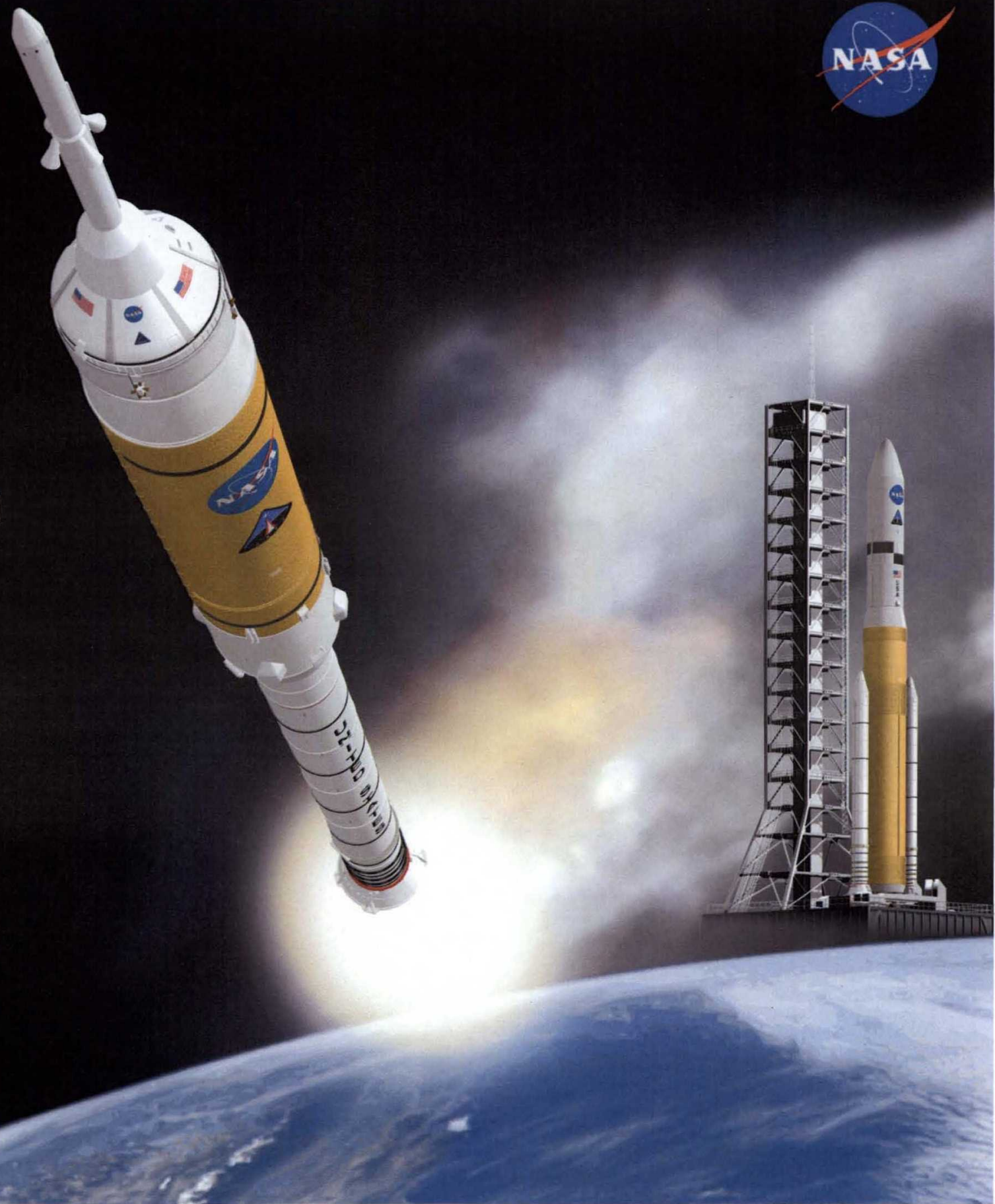

Dan Dumbacher, Director Engineering Directorate Marshall Space Flight Center 


\section{The Vision for Space Exploration}

- Complete the International Space Station.

- Safely fly the Space Shuttle until 2010.

- Develop and fly the Crew Exploration Vehicle (CEV) no later than 2014.

- Return to the Moon no later than 2020.

- Extend human presence across the solar system and beyond.

- Implement a sustained and affordable human and robotic program.

- Develop supporting innovative technologies, knowledge, and infrastructures.

- Promote international and commercial participation in exploration.

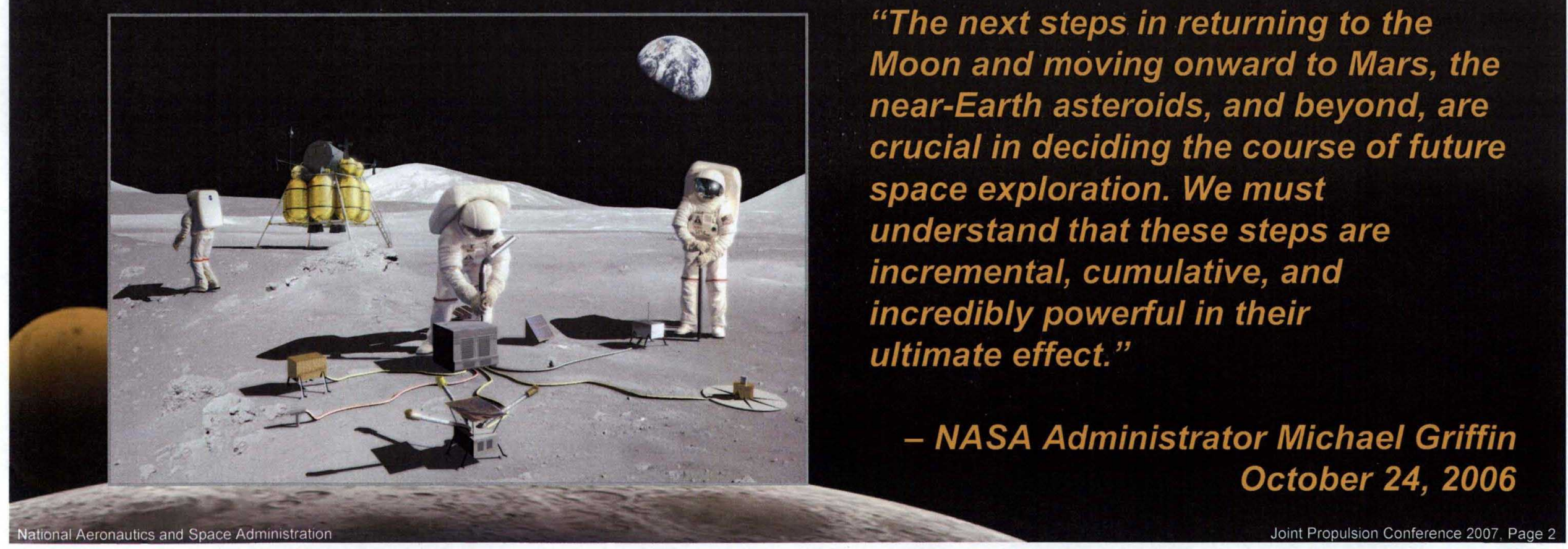




\section{NASA's Exploration Roadmap}

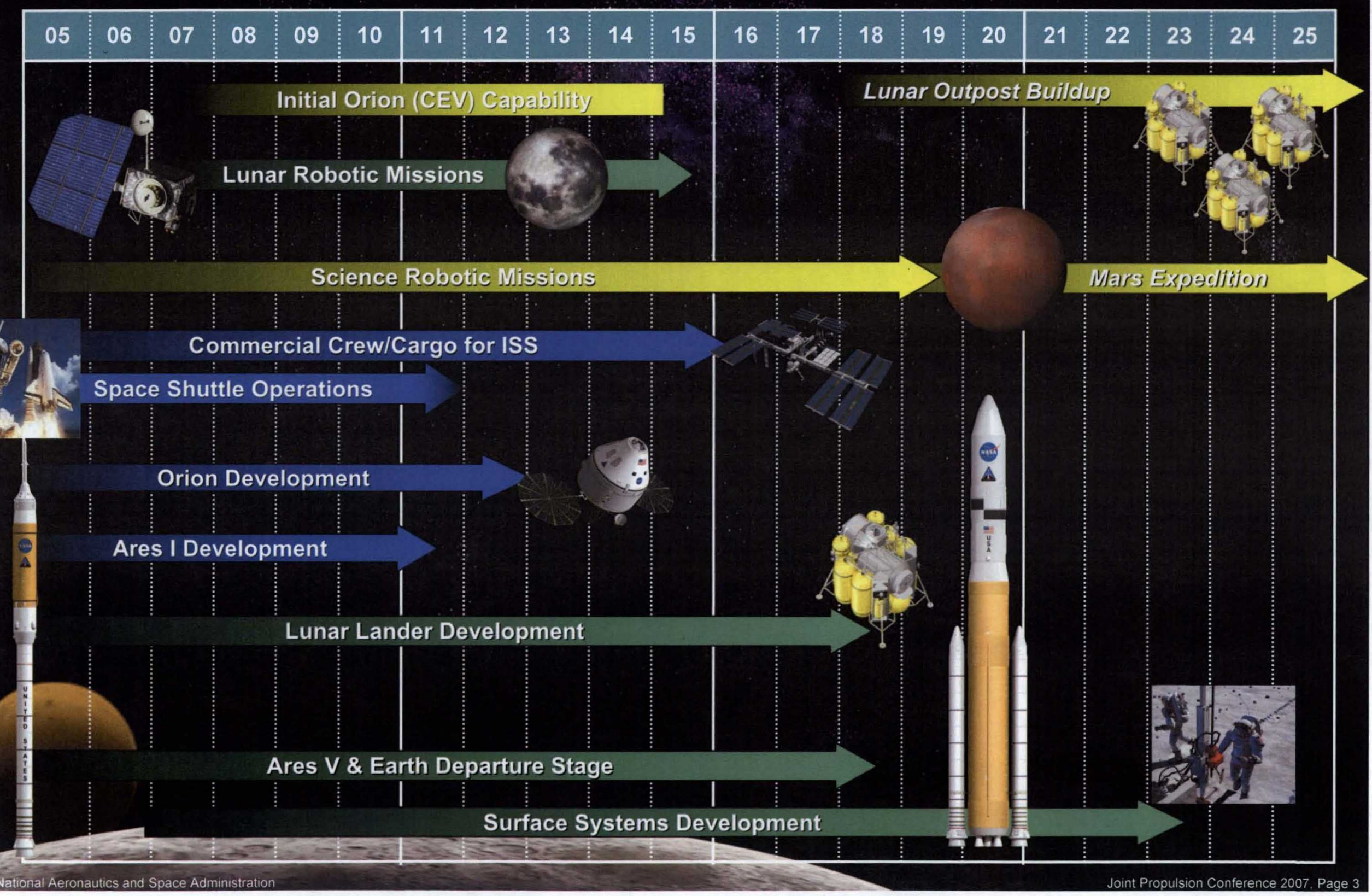




\section{Building on a Foundation of Proven Technologies \\ - Launch Vehicle Comparisons -}

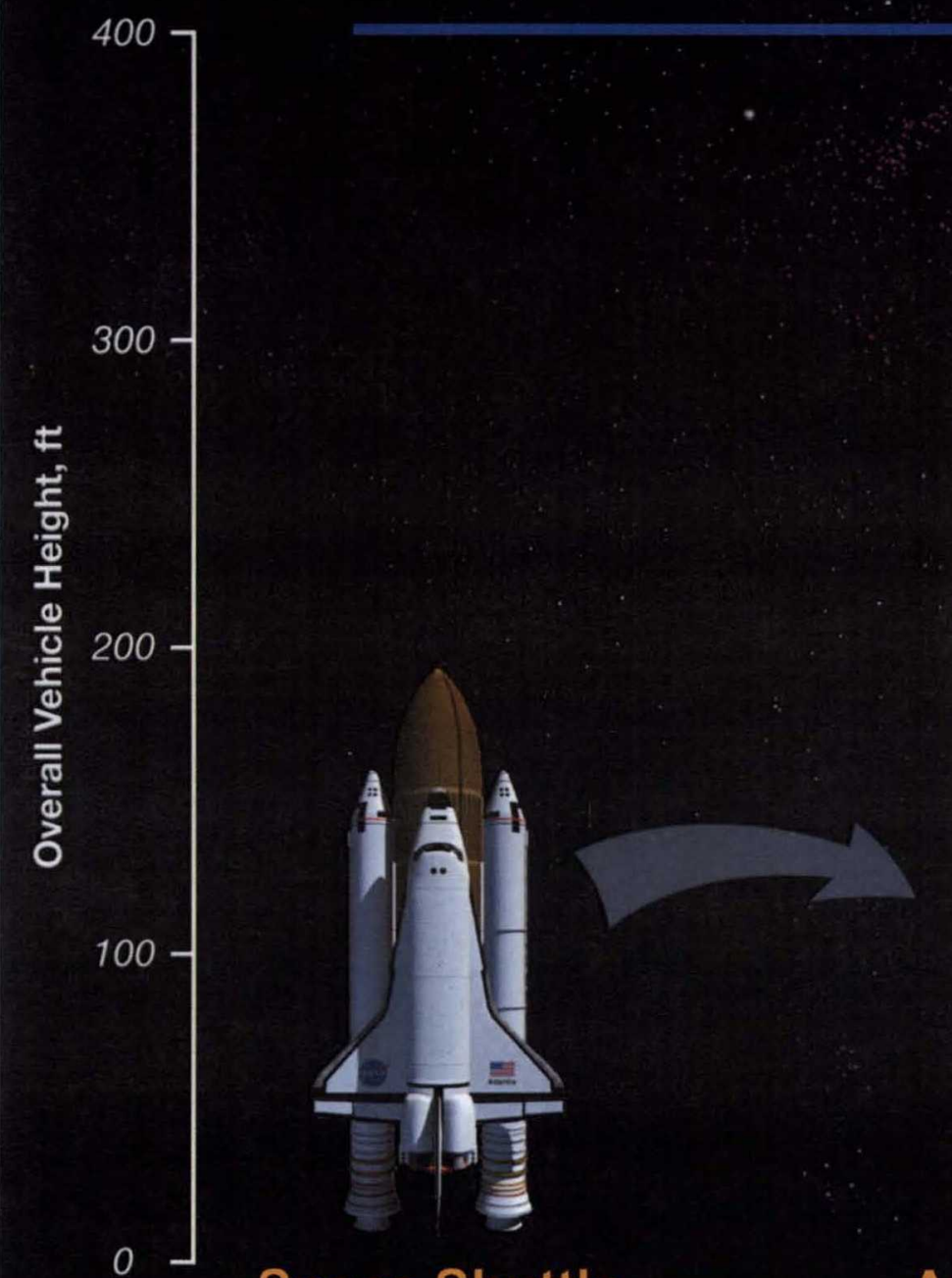

\section{Space Shuttle}

Height: $184.2 \mathrm{ft}$

Gross Liftoff Mass: $4.5 \mathrm{M} \mathrm{Ib}$

$55 \mathrm{k} \mathrm{lbm}$ to LEO

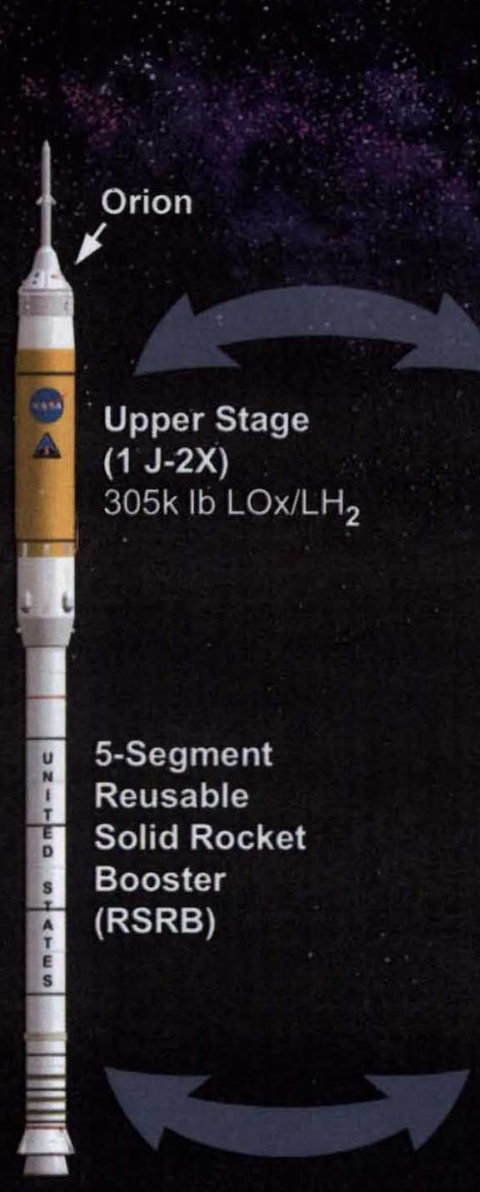

Ares I

Height: $328 \mathrm{ft}$

Gross Liftoff Mass: $2.0 \mathrm{M} \mathrm{Ib}$

$52 \mathrm{k} \mathrm{lbm}$ to LEO (effective)

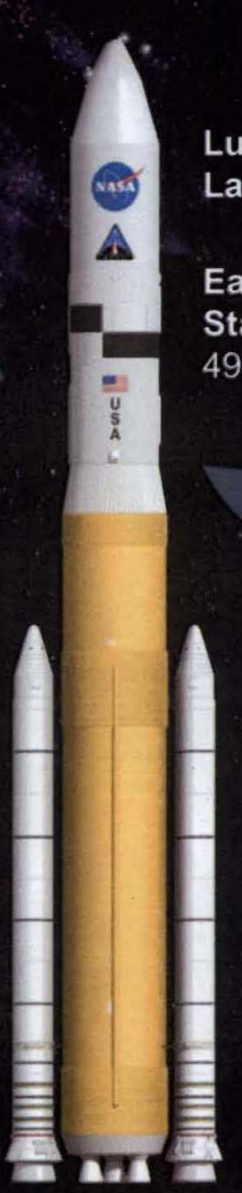

Ares V

Lunar

Lander

Earth Departure

Stage (EDS) (1 J-2X)

493k Ib LOx/LH $\mathrm{H}_{2}$

Core Stage

(5 RS-68 Engines)

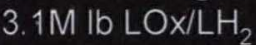

Two 5-Segment

RSRBs

Height: $362 \mathrm{ft}$

Gross Liftoff Mass: $7.3 \mathrm{M} \mathrm{lb}$

$119 \mathrm{k} \mathrm{lbm}$ to TLI

$133-144 \mathrm{k} \mathrm{lbm}^{*}$ to TLI in DualLaunch Mode with Ares I

NASA

.

rew

Lander

S-IVB

(1 J-2 engine)

240k Ib LOx/LH

S-II

(5 $\mathrm{J}-2$ engines)

$1 \mathrm{M}$ lb LOx/ $\mathrm{LH}_{2}$

S-IC

(5 F-1 engines)

3.9M lb LOX/RP 


\section{Ares: Building on Proven Capabilities}

- A 5-segment solid rocket motor was test fired in October 2003.

- The J-2X engine's predecessor made its debut during the United States' first round of Moon missions, and its turbomachinery was tested as part of the more recent X-33 Program.

- The Upper Stage will be assembled at the Michoud Assembly Facility, home of the Shuttle External Tank, using the same materials.

- The RS-68 engine, which powers the Delta IV, will boost the Ares V core stage.

- Using experienced human spaceflight workforce to process the Ares at the Kennedy Space Center using many Shuttle capabilities, such as booster processing and assembly, the Vehicle Assembly Building, and Launch Complex 39.

Using the Experienced Capabilities in a Streamlined Manner

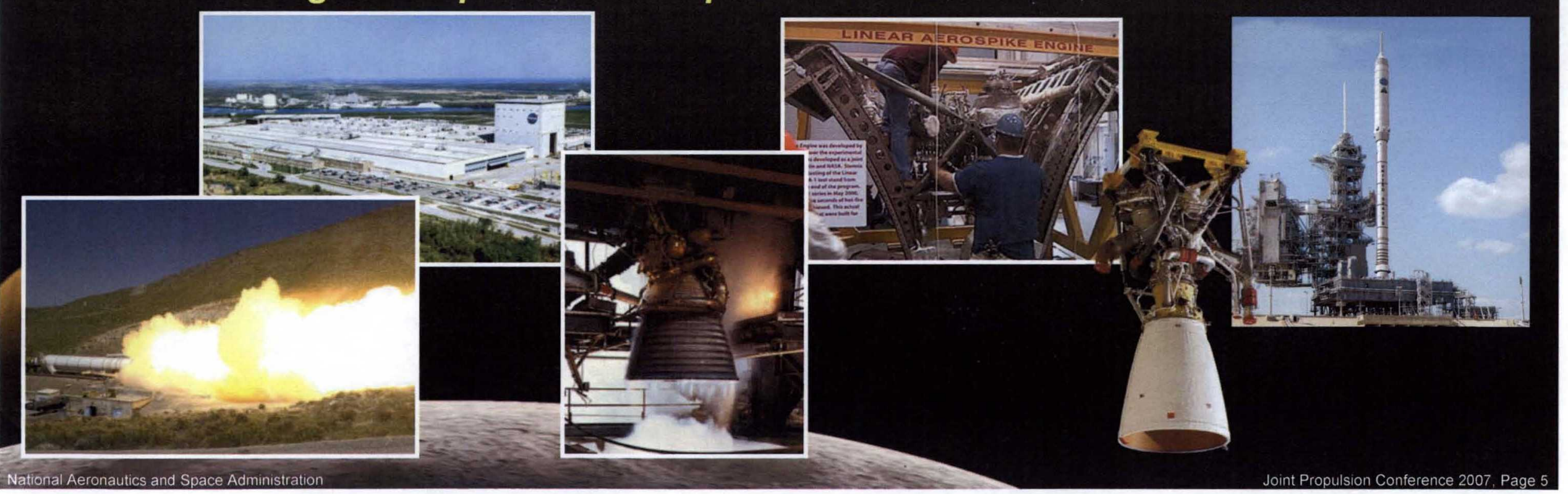




\section{Ares I-X Development Flight Test}

April 2009

- Demonstrate control of a dynamically similar, integrated CLV/CEV

- Baseline trajectory closely matches CLV through Mach 4 and key separation conditions

- Perform an in-flight separation/staging event between a CLV-similar First Stage and a representative Upper Stage.

- Demonstrate assembly and recovery of a new CLV-like First Stage element at KSC.

- Demonstrate First Stage separation sequencing, and quantify First Stage atmospheric entry dynamics, and parachute performance.

- Characterize magnitude of integrated vehicle roll torque throughout First Stage flight.
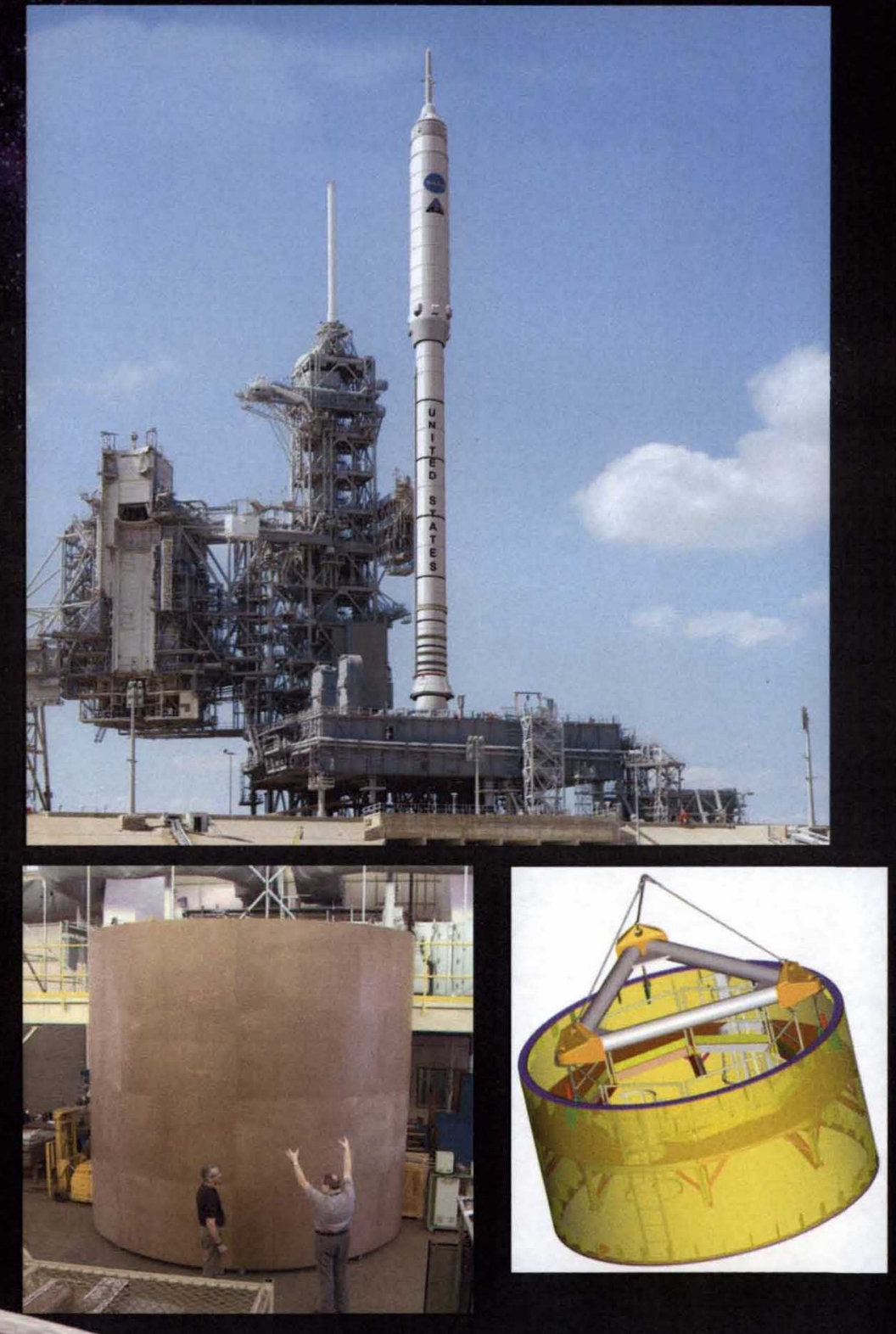


\section{Ares I Elements}

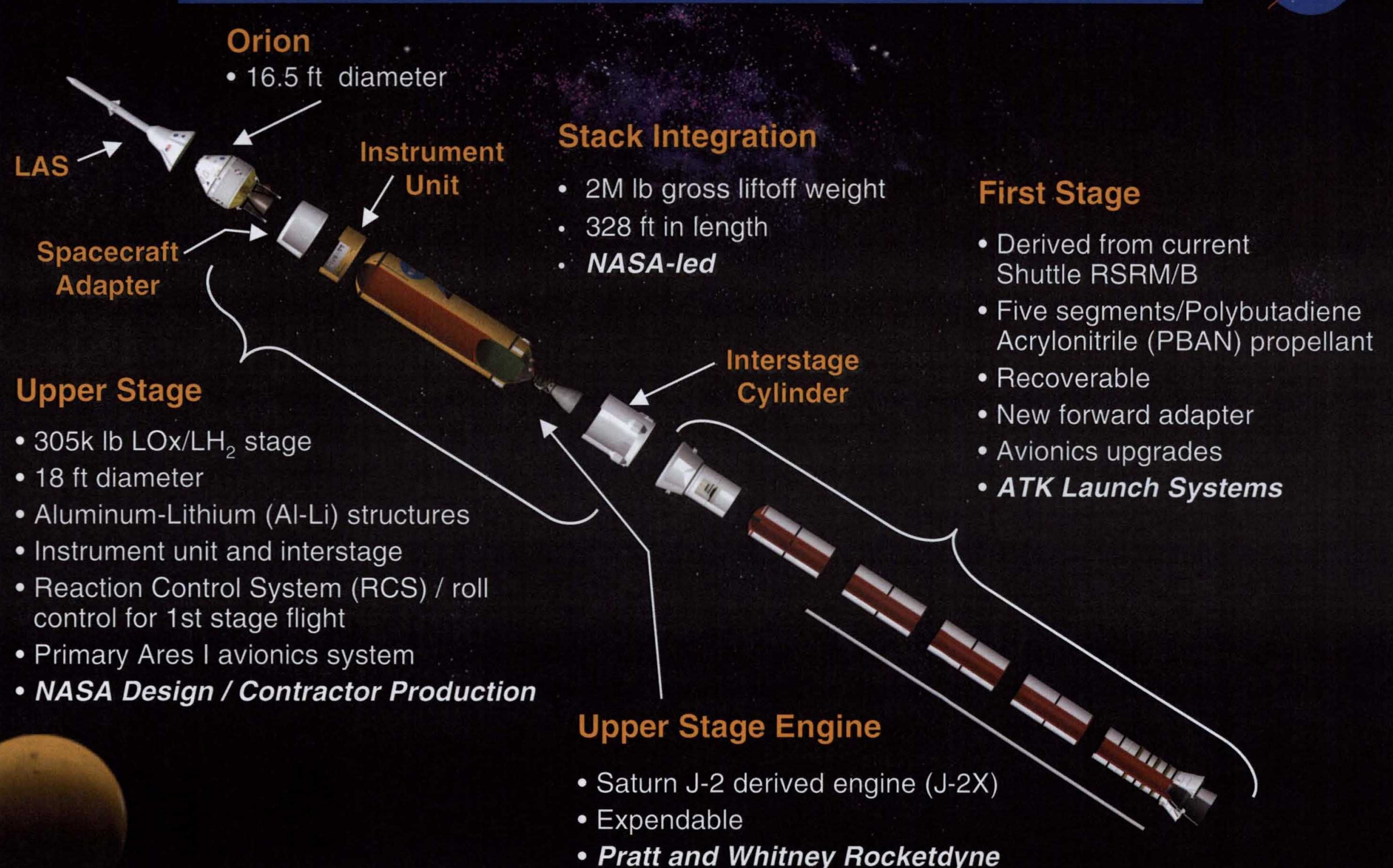




\section{Ares V Elements}

Sos

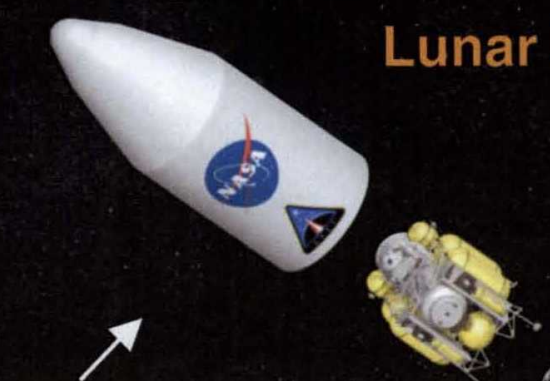

Payload

Fairing

\section{Earth Departure Stage (EDS)}

- One Saturn-derived J-2X LOx/LH $\mathrm{LH}_{2}$ engine (expendable)

- $27.5 \mathrm{ft}$ diameter stage

- Aluminum-Lithium (Al-Li)/ composite structures

- Instrument unit and Interstage

- Primary Ares V avionics system
Stack Integration

- 7.3M lb gross liftoff weight

- $362 \mathrm{ft}$ in length
First Stage

- Two recoverable five-segment PBAN-fueled boosters (derived from current Ares I First Stage)

\section{Core Stage}

- Five Delta IV-derived RS-68 $\mathrm{LOx} / \mathrm{LH}_{2}$ engines (expendable)

- $33 \mathrm{ft}$ diameter stage

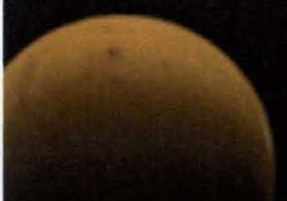

\section{Interstage}




\section{Ares Nationwide Team}

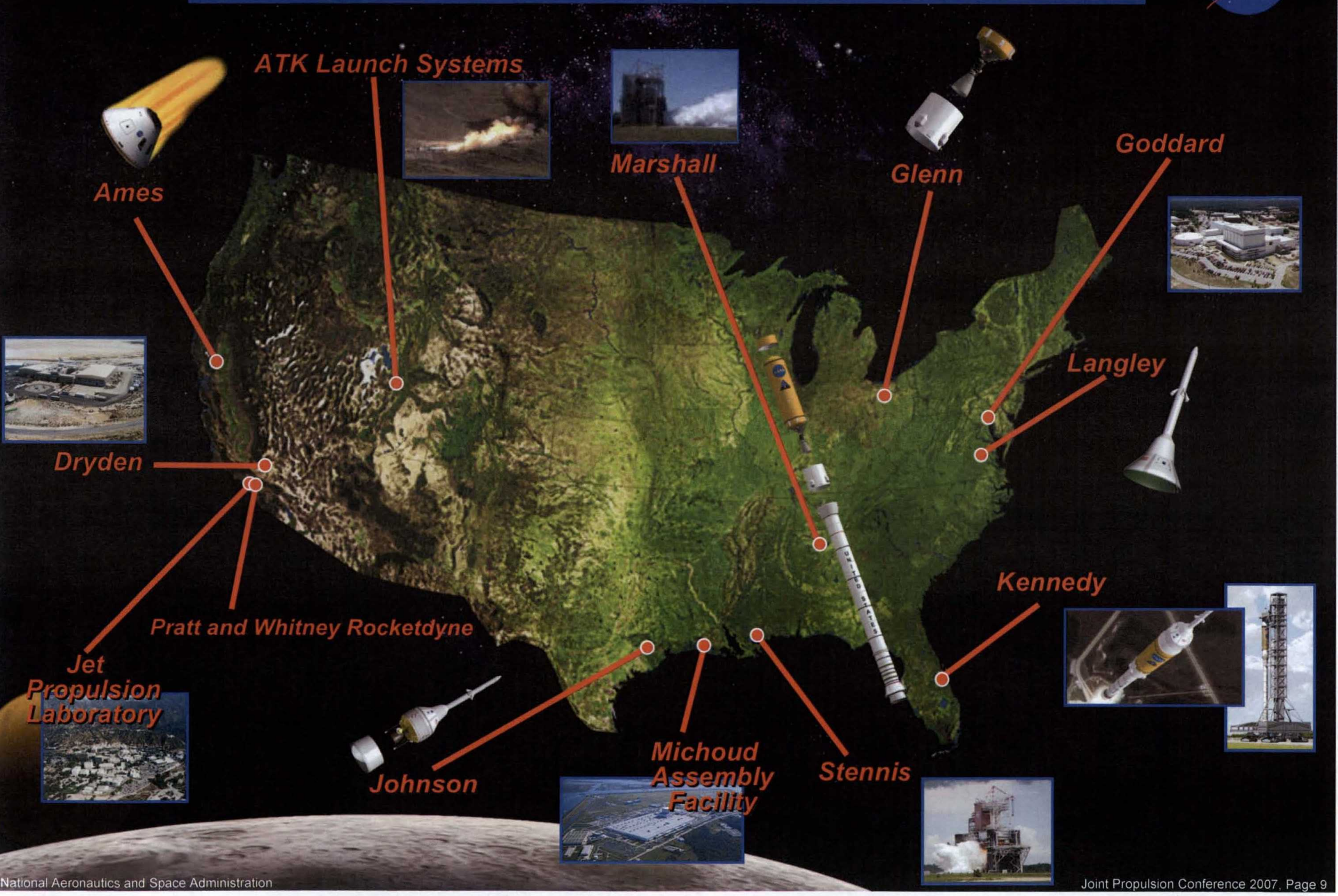




\section{Ares Milestones}

CE3-00-0043 April $\uparrow 1,2007$

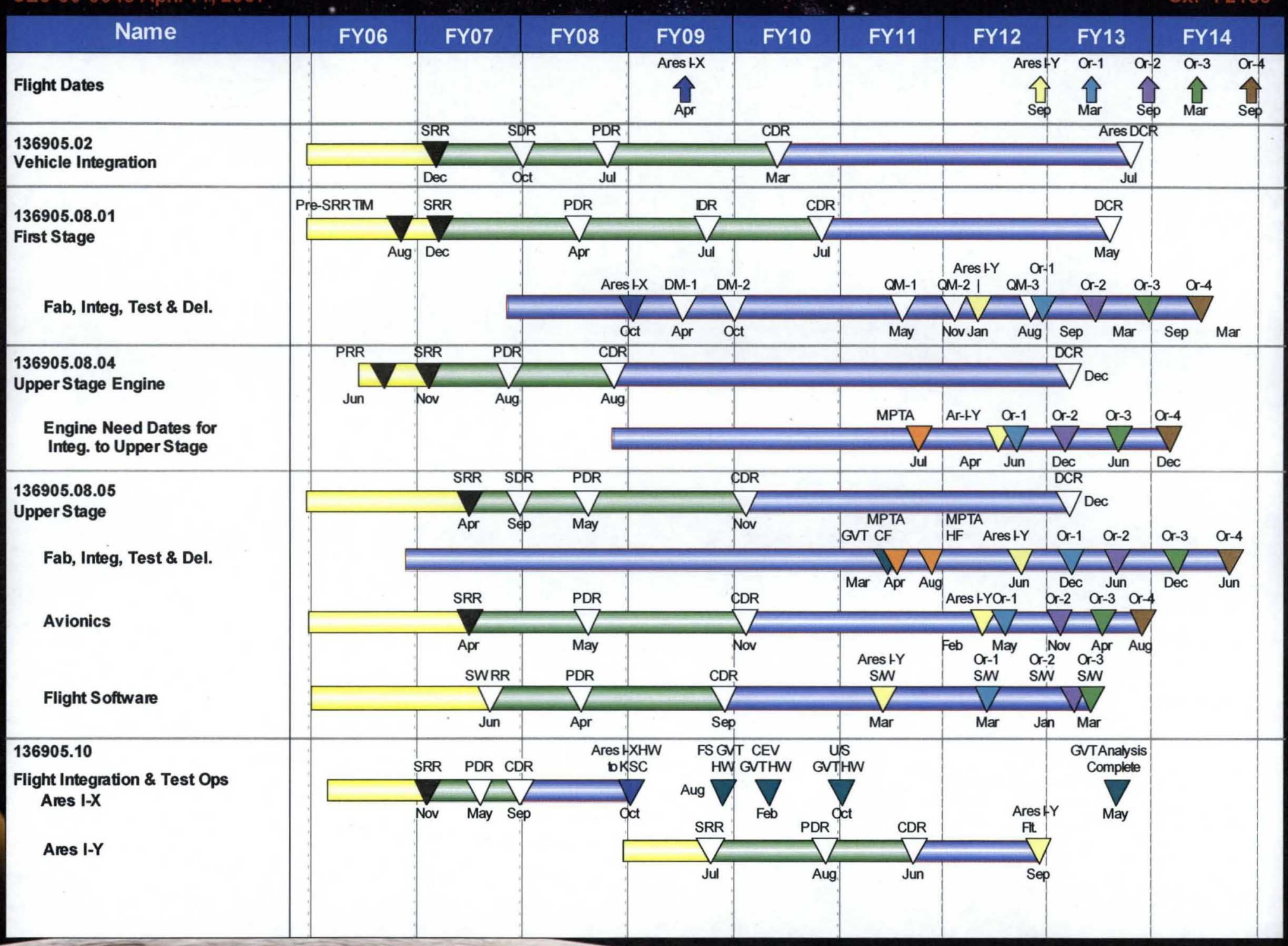




\section{Progress Toward Launch}

- Programmatic Milestones

- Completed Ares I System Requirements Reviews

- Contracts awarded for creation of Orion (Lockheed Martin), First Stage (ATK), J-2X engine (Rocketdyne), and ...

- Ares I System Design Review preparations in progress

- Ares I-X test flight scheduled for April 2009

- Technical Milestones

- Over 2,800 wind tunnel tests

- First Stage parachute testing and nozzle development

- J-2X High-Altitude test stand to be constructed at the Stennis Space Center

- J-2X injector testing and powerpack test preparation

- Upper Stage initial design analysis cycle

- Ares I-X hardware fabrication

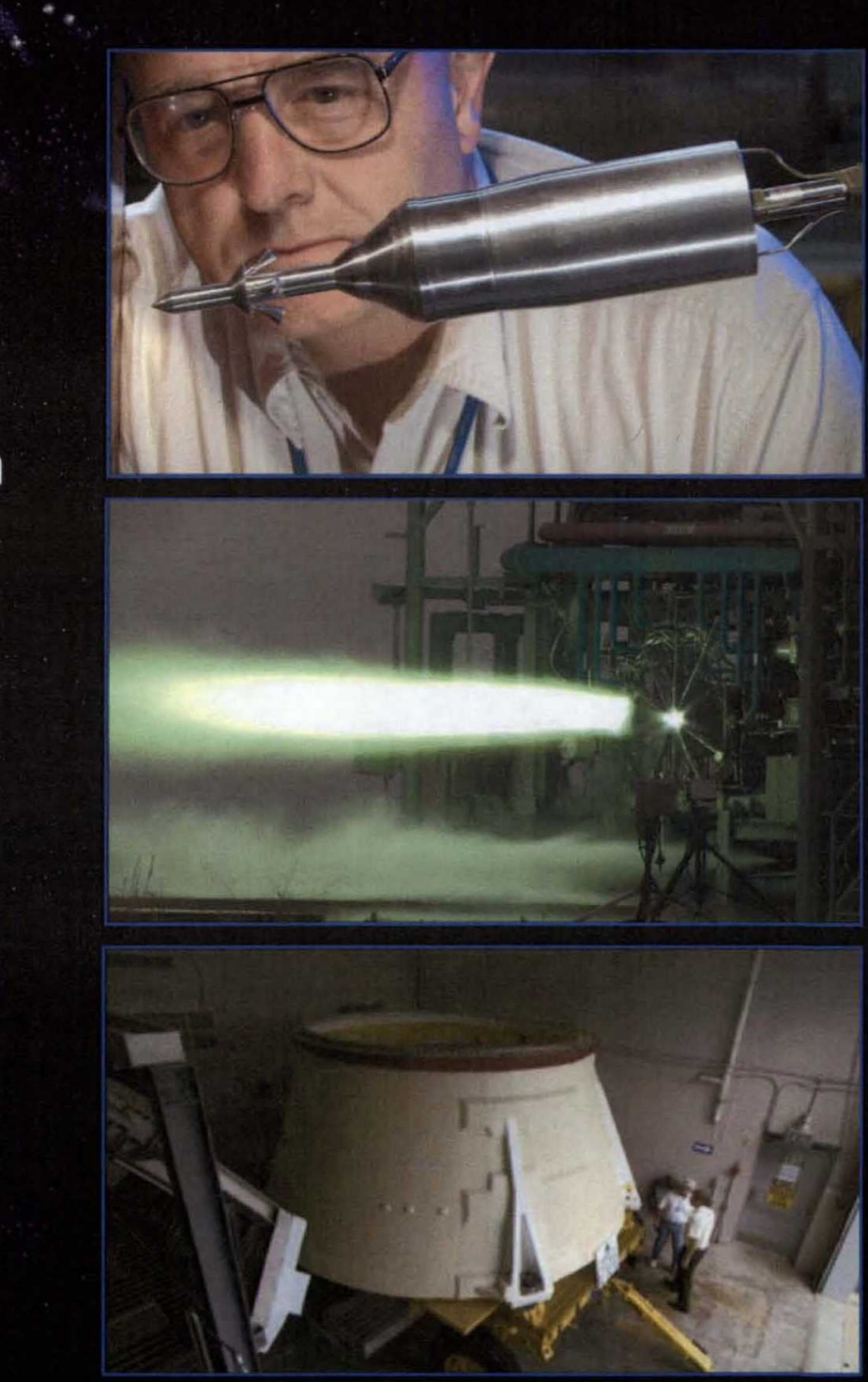




\section{Vehicle Integration}
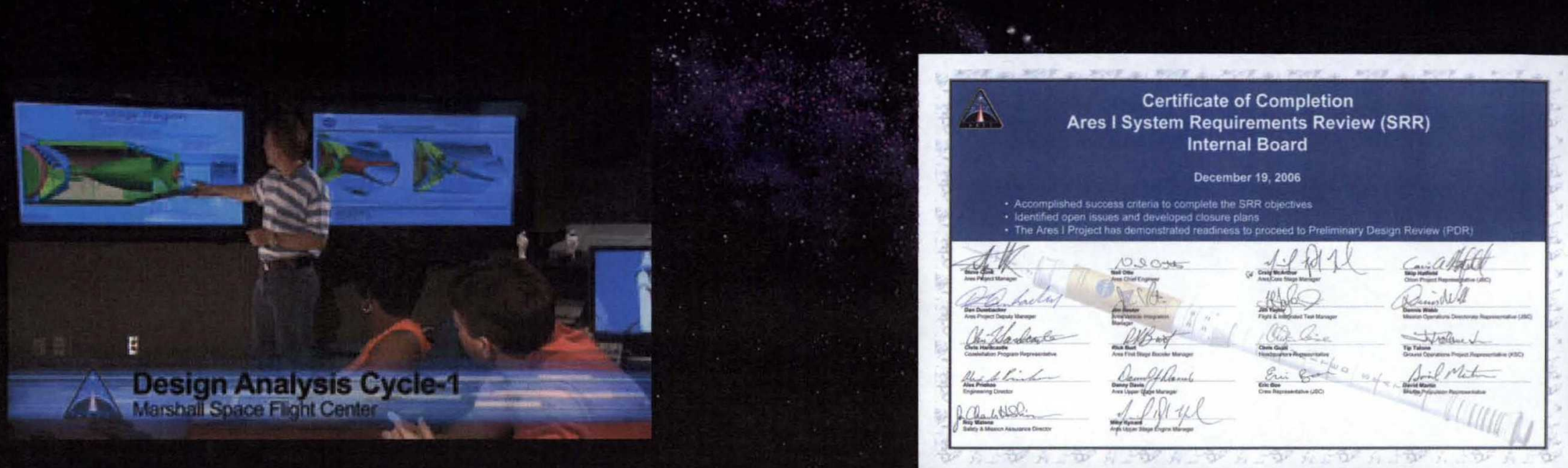

Design Analysis Cycle 1

Complete, DAC-2 Underway

Conducted Successful Ares SRR

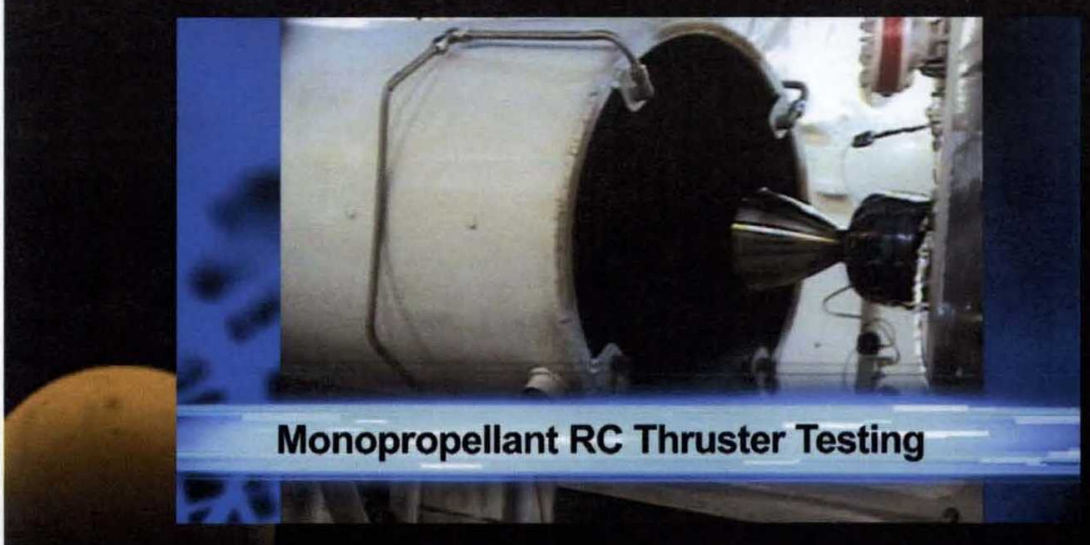

Monopropellant Reaction

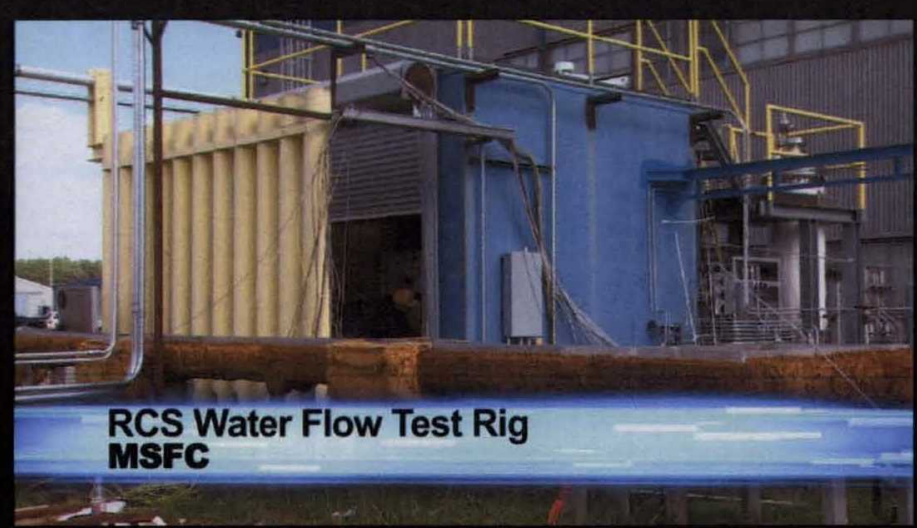

Control Thruster lesting

Reaction Control System Water Flow Test Rig 


\section{First Stage Development \& Test}

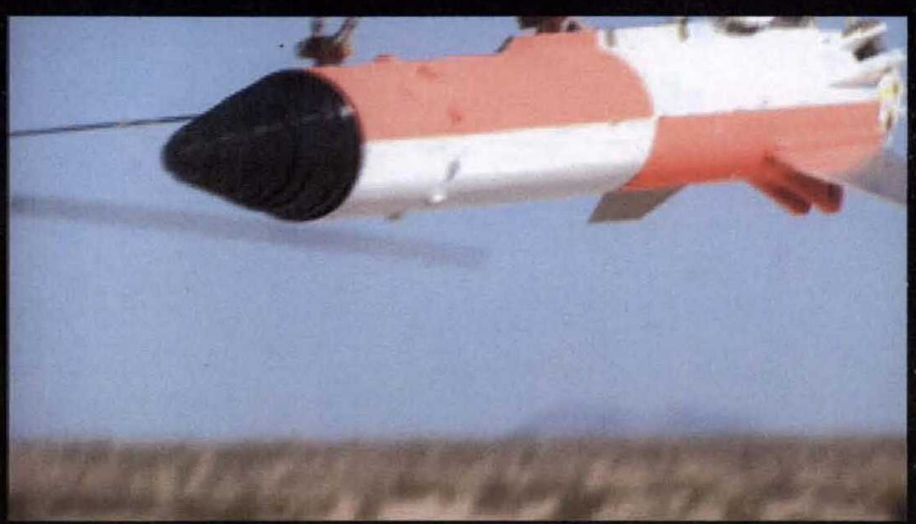

Pilot Parachute Testing - Yuma Proving Ground

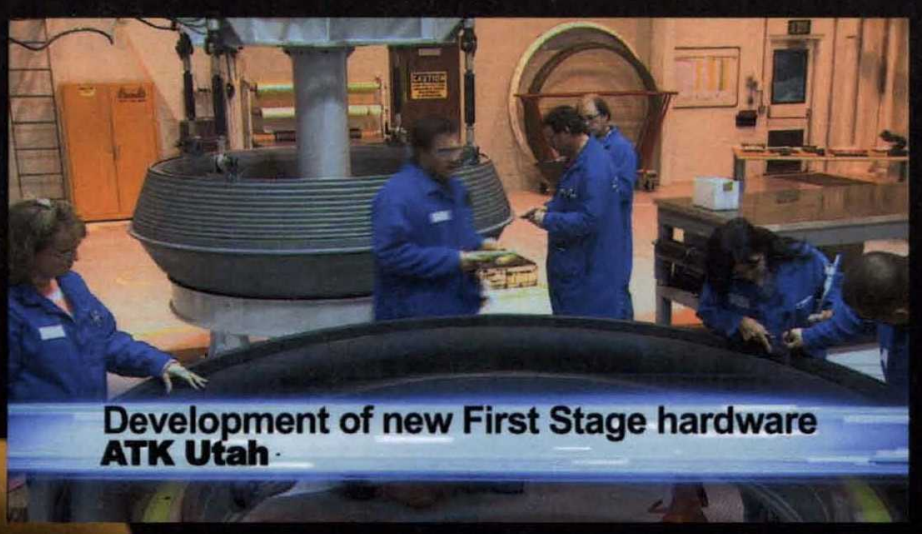

Development of new First Stage Hardware - ATK

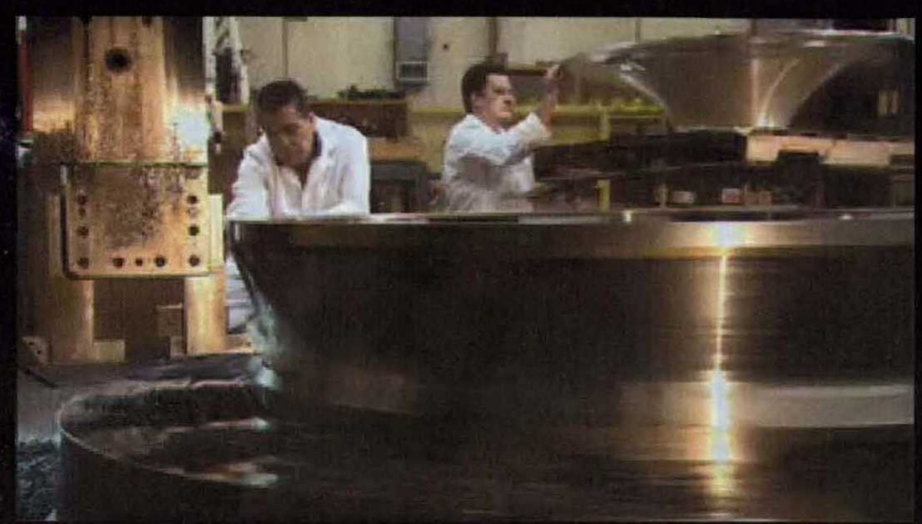

New Nozzle Hardware - Votaw Precision Technologies

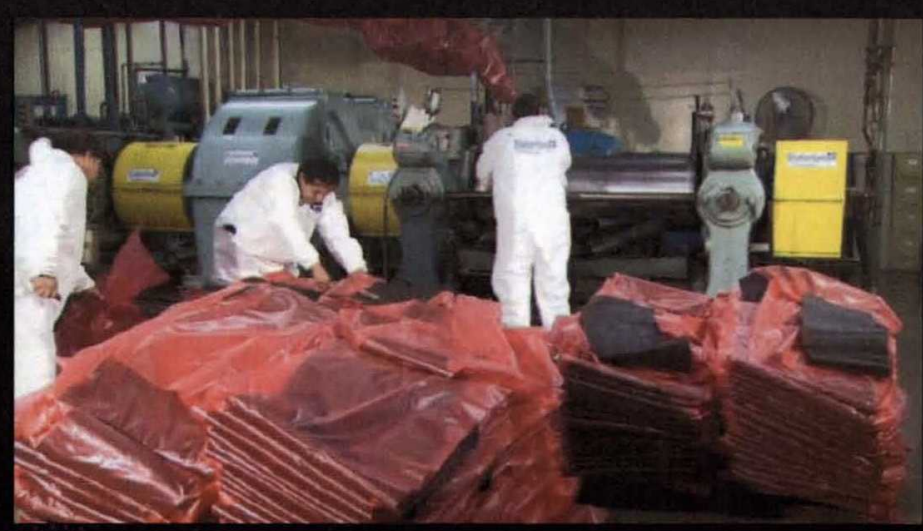

Development of new First Stage Motor Insulation 


\section{Upper Stage Engine}

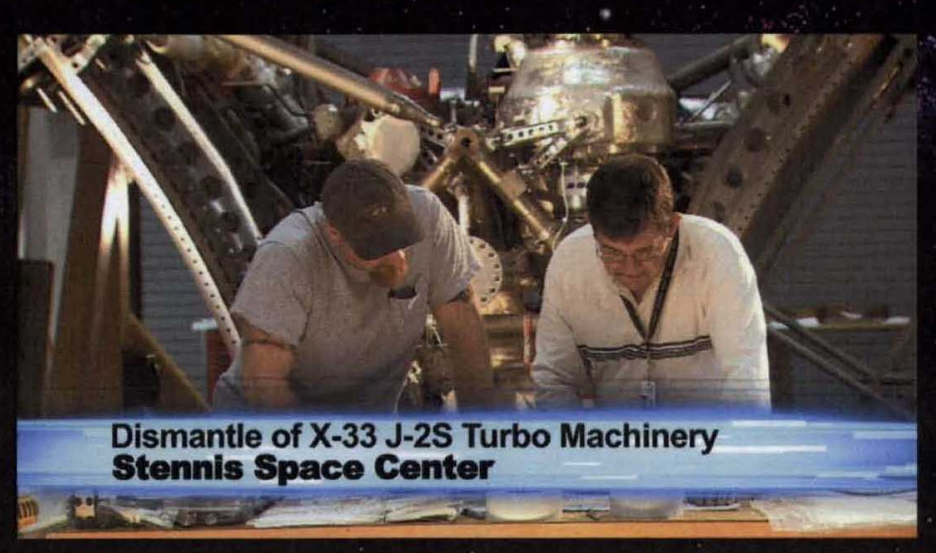

Dismantle of X-33 J-2S Turbo

Machinery - Stennis

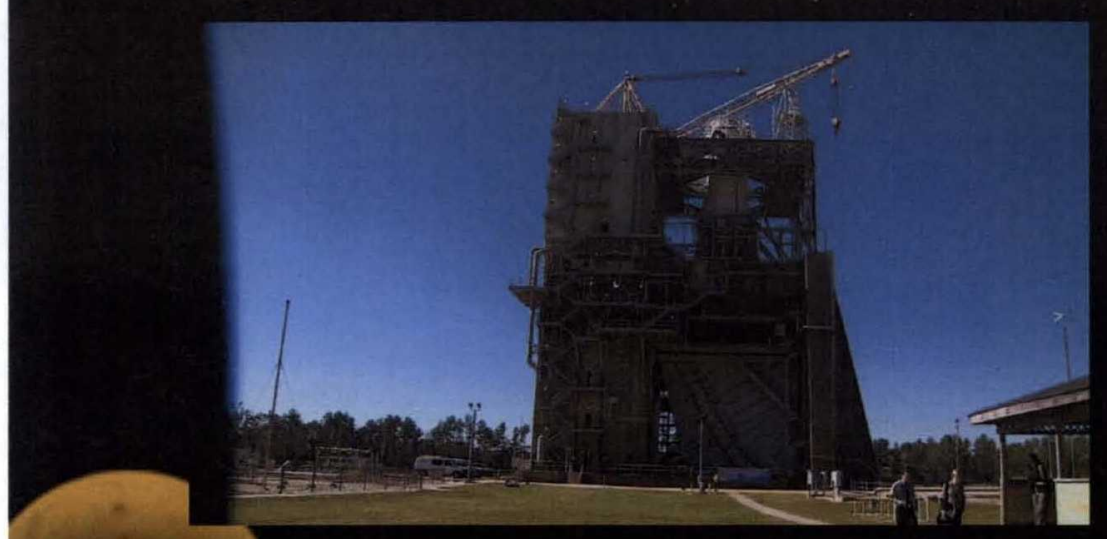

Test Stand A-I Handover to Ares

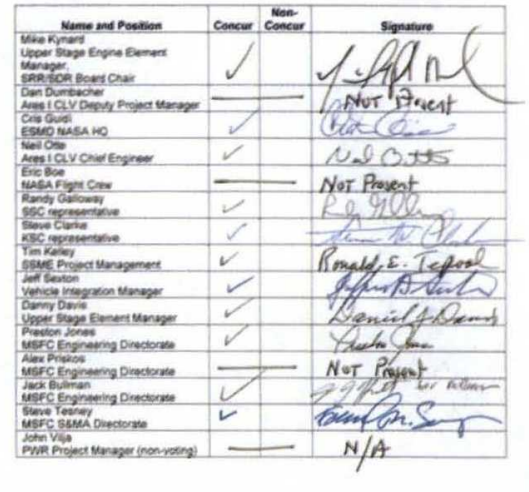

Conducted Successful Upper Stage Engine SRR/SDR

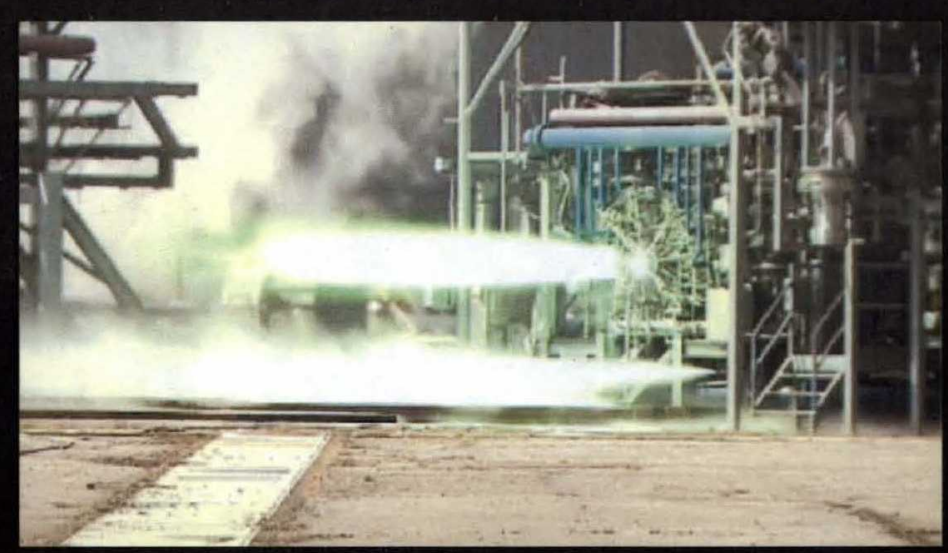

Subscale Injector Testing 


\section{Upper Stage}

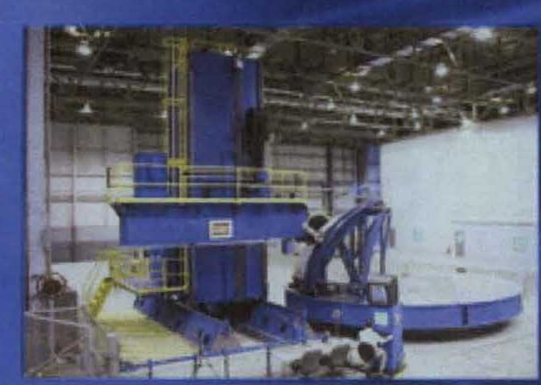

New Welding Fixture Installation at MSFC

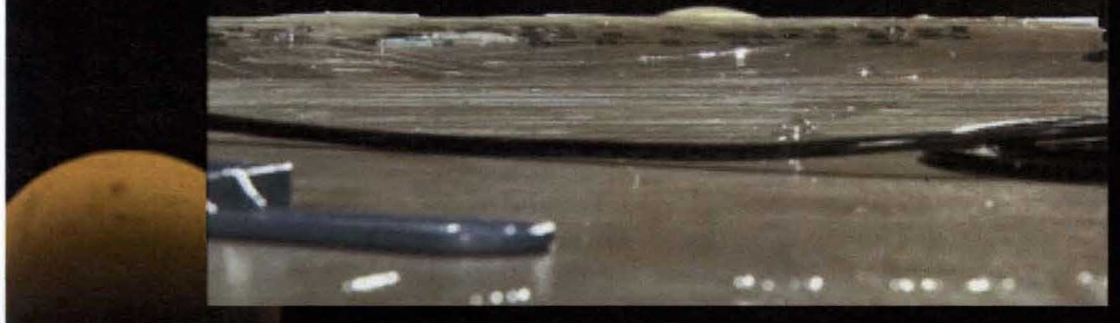

Non-destructive Testing

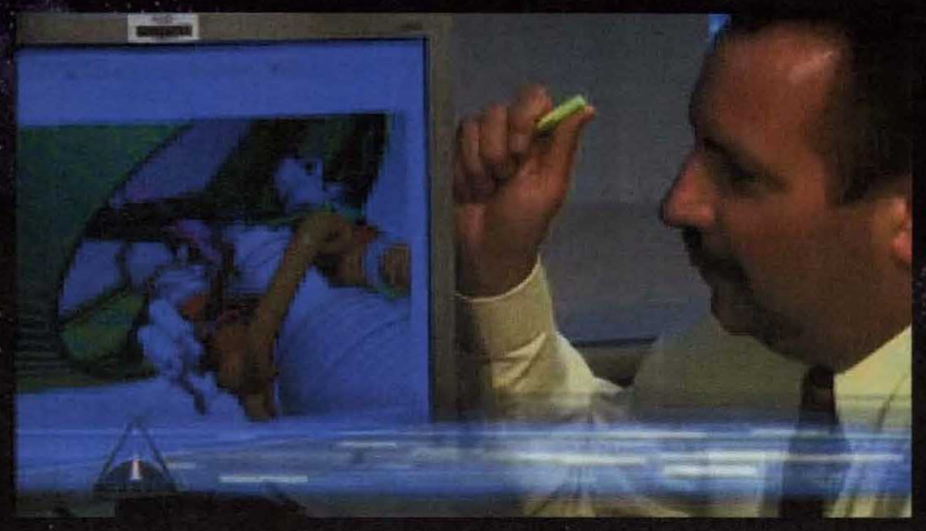

$\mathrm{J}-2 \mathrm{X}$ Actuator Design

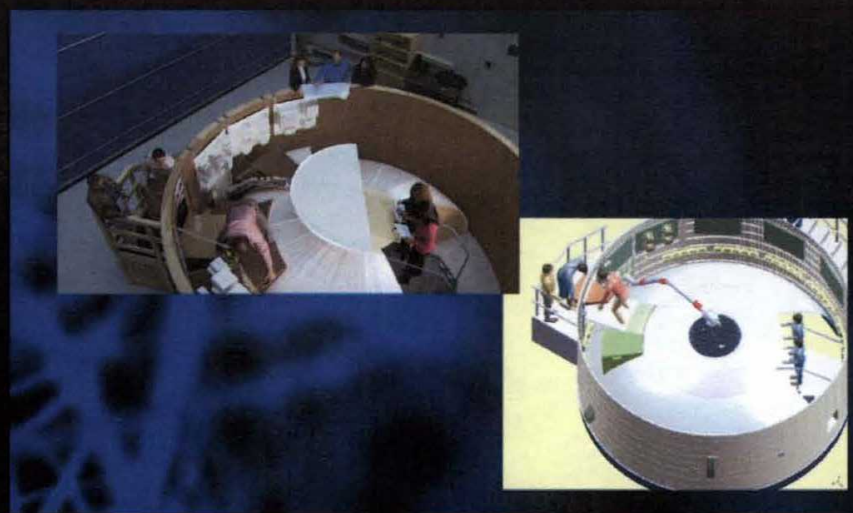

Mock-up of Ares I Instrument Unit with CAD Imagery 


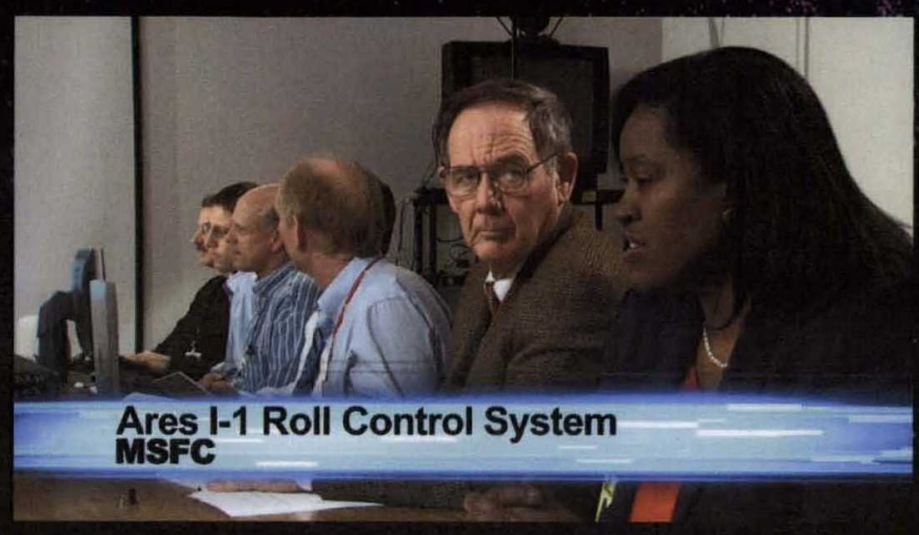

Ares I-X Roll Control System

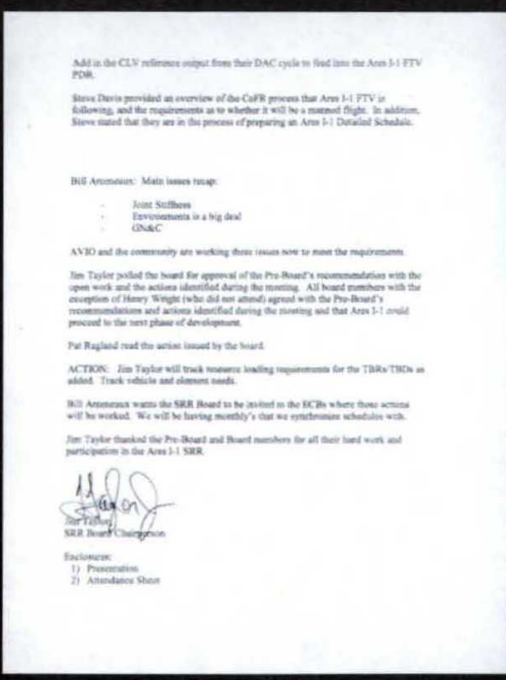

Conducted Successful

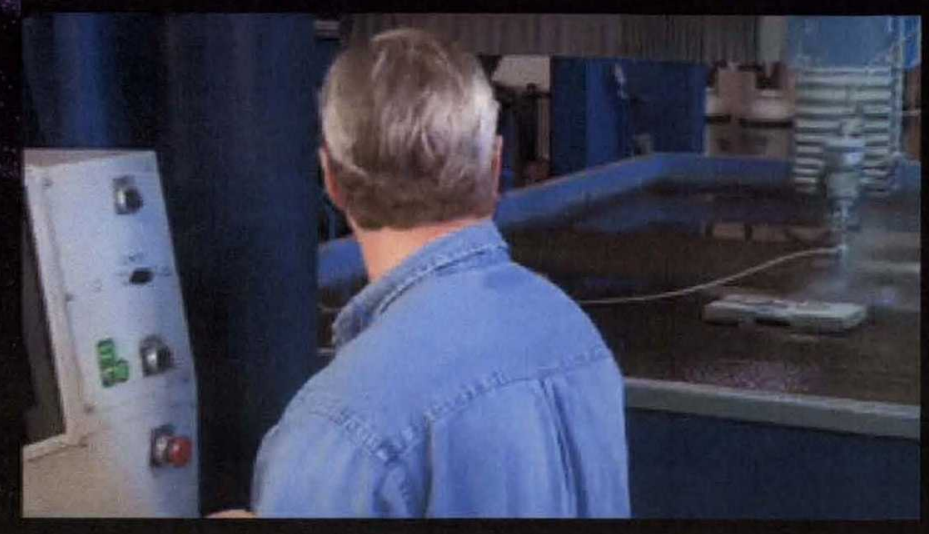

Fabrication of the Ares I-X Flight Hardware

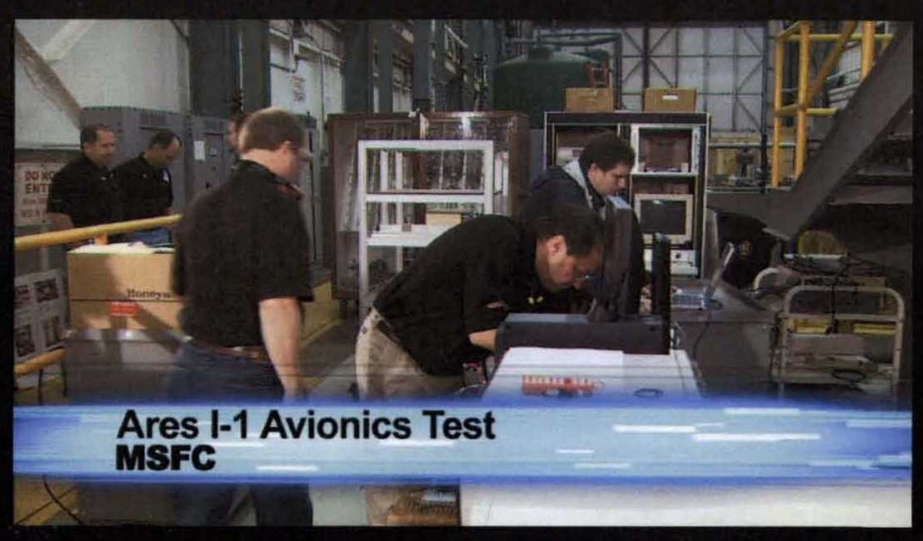

Ares I-X Avionics / SRB Thrust Vector Control Test 


\section{Summary}

- We must build beyond our current capability to ferry astronauts and cargo to low Earth orbit.

-We are designing and building these new vehicles using extensive lessons learned to minimize cost, technical, and schedule risks.

- To reach for Mars and beyond we must first reach for the Moon.

- The team has completed requirements analysis and is now engaged in detailed vehicle design.

We need you, the owners, to help make this happen!

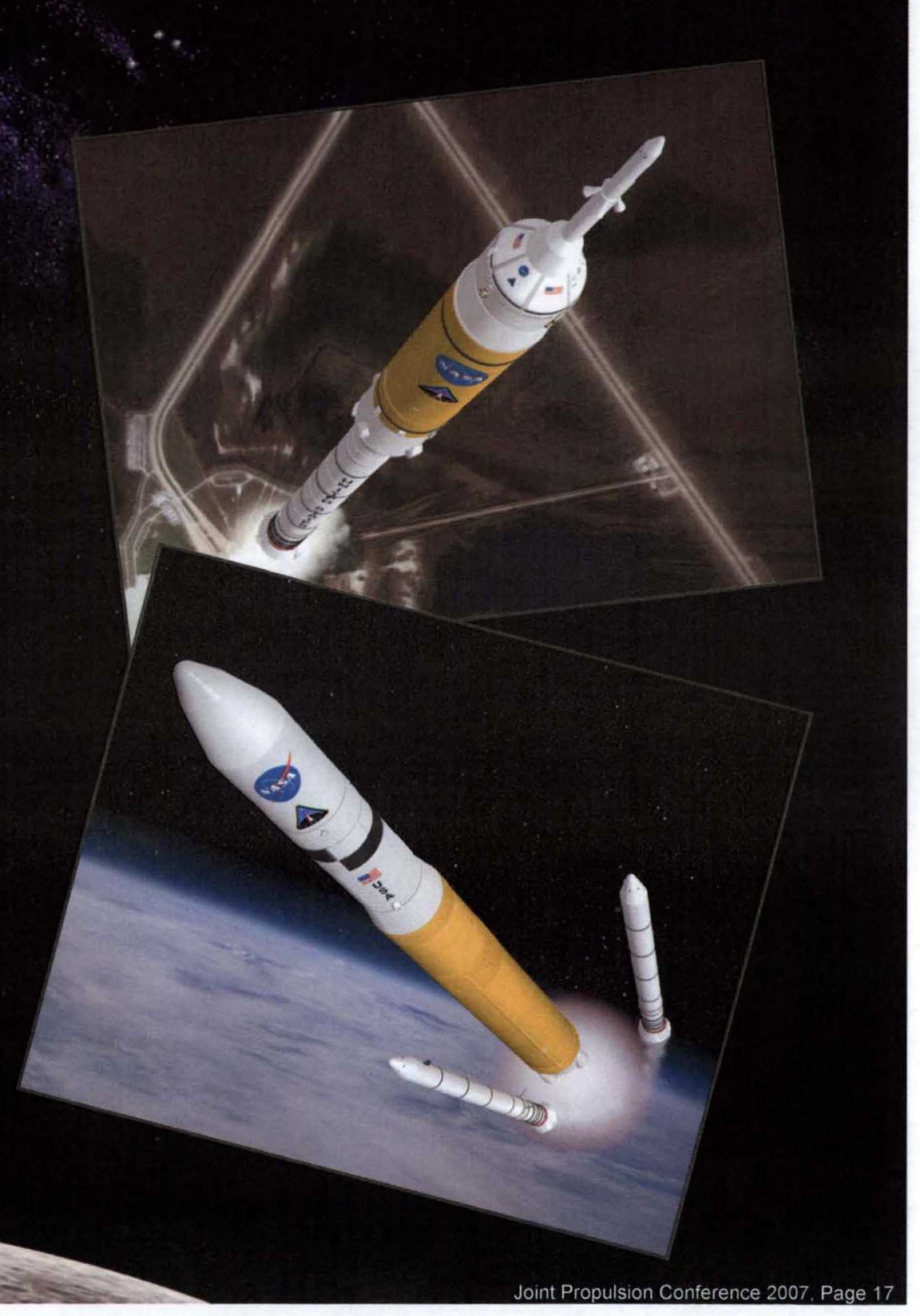




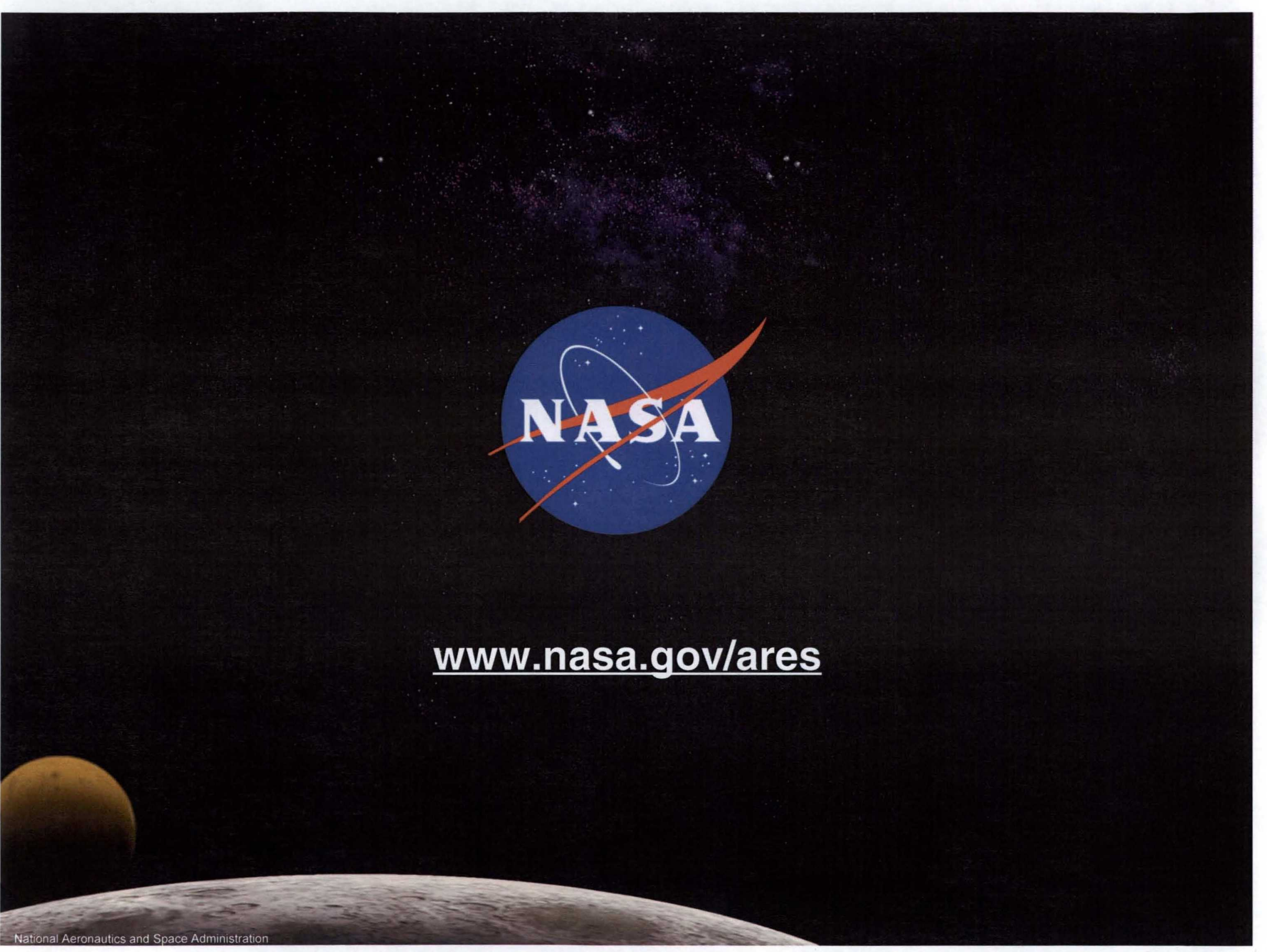

